OPEN ACCESS

Edited by:

Inge Dagmar Wijnberg, Utrecht University, Netherlands

Reviewed by:

Dilip Kumar Garikipati, Cleveland Clinic, United States

Marie-France Roy,

University of Calgary, Canada

${ }^{*}$ Correspondence: M. Katie Sheats mkpeed@ncsu.edu

Specialty section

This article was submitted to Comparative and Clinical Medicine,

a section of the journal

Frontiers in Veterinary Science

Received: 16 January 2018

Accepted: 15 February 2019

Published: 12 March 2019

Citation:

Sheats MK (2019) A Comparative

Review of Equine SIRS, Sepsis, and

Neutrophils. Front. Vet. Sci. 6:69.

doi: 10.3389/fvets.2019.00069

\title{
A Comparative Review of Equine SIRS, Sepsis, and Neutrophils
}

\author{
M. Katie Sheats* \\ Department of Clinical Sciences, North Carolina State University College of Veterinary Medicine, Raleigh, NC, United States
}

The most recent definition of sepsis in human medicine can be summarized as organ dysfunction caused by a dysregulated host response to infection. In equine medicine, although no consensus definition is available, sepsis is commonly described as a dysregulated host systemic inflammatory response to infection. Defense against host infection is the primary role of innate immune cells known as neutrophils. Neutrophils also contribute to host injury during sepsis, making them important potential targets for sepsis prevention, diagnosis, and treatment. This review will present both historical and updated perspectives on the systemic inflammatory response (SIRS) and sepsis; it will also discuss the impact of sepsis on neutrophils, and the impact of neutrophils during sepsis. Future identification of clinically relevant sepsis diagnosis and therapy depends on a more thorough understanding of disease pathogenesis across species. To gain this understanding, there is a critical need for research that utilizes a clearly defined, and consistently applied, classification system for patients diagnosed with, and at risk of developing, sepsis.

Keywords: sepsis, systemic inflammatory response, neutrophil, endotoxemia, organ dysfunction

\section{INTRODUCTION - THE IMPACT OF SEPSIS}

The Society of Critical Care Medicine and the European Society of Critical Care Medicine task force define sepsis as life-threatening organ dysfunction caused by a dysregulated host response to infection (1). Sepsis claims millions of human lives worldwide each year, and in North America alone, more than 750,000 people develop sepsis annually (2). While the sepsis mortality rate in humans appears to be declining (27\% in 2007 , down from $39 \%$ in 2000) (3), the continued rise in the rate of sepsis diagnosis, which reportedly doubled between 2000 and 2008 (4), made it the 11th leading cause of death in the United States in 2010 (5). From a national health perspective, the impact of sepsis is significant, as the Healthcare Cost and Utilization Project (HCUP) identified sepsis as the single most expensive condition treated in hospitals in 2011, with a total aggregated cost of $\$ 24$ billion (6). Because of its impact, sepsis continues to be the focus of intense research in which the current understanding of pathophysiology is being reevaluated, the relevance of various in vitro and in vivo models is being challenged (7-9) and the importance of species-specific differences is being recognized (10). With advanced information and understanding, clinicians, and basic scientists will be able to develop new approaches and new targets for the treatment and even prevention of this devastating condition. 
While there are still fewer reports on the cost and incidence of sepsis in horses compared to humans, significant progress has been made in recent years to better understand the impact of sepsis diagnosis on equine patient outcomes, particularly in foals. Sepsis is one of the most common reasons for neonatal foals to present to tertiary care veterinary hospitals $(11,12)$. In a recent retrospective study, Giguere et al. reported on the primary and secondary diagnoses of 1,065 equine neonates $\leq 14$ days of age presented to an intensive care unit (ICU) between 1982 and 2008 (13). These authors report that 453 of the 1,065 foals $(42.5 \%)$ had a positive blood culture, and 641 of the 1,065 foals $(60.2 \%)$ were classified as septic. In this study, sepsis was defined as any or all of the following criteria: (1) positive blood culture, (2) more than 1 site of infection ante mortem, or (3) post mortem evidence of more than 1 septic process. One of the more interesting findings to come from this research is the evidence that survival of foals admitted to neonatal ICUs, although not specifically for sepsis, has increased significantly over the past 3 decades. In another multicenter study of hospitalized equine neonates, Wong et al. reported that 147 of 273 (46\%) foals $\leq 30$ days of age were classified as septic (14). Foals in this study were classified as septic based on the same criteria reported by Weber et al. (15). Wong et al. reported that $73 \%$ (92 of 126) of septic foals in their study survived to discharge (14). Overall, reported survival rates for foals with sepsis varies from $45-81 \%$, with significant variability in sample population and sepsis definition between studies (1622). In terms of financial cost, one prospective study reported that the mean cost of hospitalization and treatment for foals that survived sepsis was $\$ 2842.00$ (23); but based on severity of illness and duration of hospitalization, the individual patient costs can be much higher.

In contrast to the larger number of studies that have examined the impact of sepsis on survival in hospitalized foals, studies on sepsis mortality in adult horses are rare. In 2017, Arroyo et al. reported on factors associated with survival in 97 horses with septic pleuropneumonia (24). In this paper, sepsis was defined as the presence of systemic inflammatory response syndrome (SIRS) and a positive bacterial culture from a tracheal aspirate or pleural fluid. Sixty-five of the 97 horses (67\%) with septic pleuropneumonia survived to discharge. Other recent studies on mortality of hospitalized adult horses have chosen to examine outcomes in patients with diagnoses other than sepsis, including endotoxemia $(25,26)$, SIRS $(27,28)$ and multiple organ dysfunction syndrome (MODS) $(29,30)$. Until consensus definitions are available to equine practitioners, the impact of sepsis on survival in adult horses is likely to remain unknown (31).

\section{DEFINING SEPSIS}

In 1991, Roger C. Bone chaired a "Consensus Conference" of the American College of Chest Physicians (ACCP) and the Society of Critical Care Medicine (SCCM), which was tasked with the "goal of agreeing on a set of definitions that could be applied to patients with sepsis and its sequelae" (32). It was expected that the definitions developed would be broad enough to improve early bedside detection of sepsis in order to allow for early therapeutic intervention. It was also anticipated that consensus on sepsis definitions would help to standardize research protocols, which would lead to "improved dissemination and application of information derived from clinical studies" (33). The result was the development of a broad series of definitions (Table 1) that is still used in practice today and has served as the basis for numerous human clinical trial inclusion criteria over the past two decades (34).

Importantly, as a result of this conference the term "systemic inflammatory response syndrome" (SIRS) was put forward as a criterion of the sepsis definition. SIRS was described as a nonspecific, clinical, pro-inflammatory immune response. While it was understood at the time that SIRS can occur in response to numerous events that injure host tissue (i.e., trauma, anaphylaxis, ischemia, hemorrhage), in the case of sepsis, the inciting event for SIRS is documented or suspected infection. As defined by Bone et al. SIRS is present when human patients experience 2 or more of the following acutely altered physiologic changes, in the absence of other known cause for such abnormalities:

- Body temperature $>38^{\circ} \mathrm{C}\left(100.4^{\circ} \mathrm{F}\right)$ or $<36^{\circ} \mathrm{C}\left(96.8^{\circ} \mathrm{F}\right)$

- Heart rate $>90$ beats $/ \mathrm{min}$

- Hyperventilation (respiratory rate $>20$ breaths $/ \mathrm{min}$ or $\mathrm{PaCO} 2$ $<32 \mathrm{mmHg}$ )

- White blood cell count $>12,000$ cells $/ \mu 1$ or $<4,000$ cells $/ \mu 1$ or $>10 \%$ band forms

The definition of SIRS proposed by Bone et al. along with the definitions of "sepsis," "severe sepsis" and "septic shock," has also gained general acceptance within veterinary medicine and are cited in equine specific-reviews on sepsis $(35,36)$. Although no consensus definition of sepsis in veterinary species is currently available, examples of published criteria used to diagnose SIRS include two or more of the following in adult horses (37):

- Body temperature $>38.6^{\circ} \mathrm{C}\left(101.5^{\circ} \mathrm{F}\right)$

- Heart rate $>60$ beats $/ \mathrm{min}$

- Hyperventilation (respiratory rate $>30$ breaths $/ \mathrm{min}$ )

- White blood cell count $>12,500$ cells $/ \mu 1$ or $<4,500$ cells $/ \mu l$ and $10 \%$ band neutrophils

and two or more of the following in equine neonates (18):

- Body temperature $>39.2^{\circ} \mathrm{C}\left(102.6^{\circ} \mathrm{F}\right)$ or $<37.2^{\circ} \mathrm{C}\left(99^{\circ} \mathrm{F}\right)$

- Heart rate $>120$ beats $/ \mathrm{min}$

- Hyperventilation (respiratory rate $>30$ breaths $/$ min)

- White blood cell count $>12,900$ cells/ $\mu$ l or $<4,000$ cells/ $\mu l$, or $>10 \%$ band neutrophils

- and evidence of sepsis, cerebral ischemia or hypoxia, or trauma

Using these criteria, researchers determined that SIRS was present in $30 \%$ of adult horses with colic (37) and more than $40 \%$ of critically ill neonatal foals (18) who presented to a teaching hospital for evaluation and treatment.

In 2001, a second International Sepsis Definitions Conference convened to respond to growing criticisms from experts in the field that the 1991 ACCP/SCCM definitions did not reflect an upto-date understanding of the pathophysiology of human sepsis and its associated syndromes and were contributing to erroneous 
TABLE 1 | ACCP/SCCM consensus conference definitions (1991).

\section{ACCP/SCCM consensus conference definitions}

Sepsis - The clinical syndrome defined by the presence of both infection and a systemic inflammatory response.

Severe sepsis-Sepsis associated with organ dysfunction, hypoperfusion, or hypotension. Hypoperfusion and perfusion abnormalities may include, but are not limited to lactic acidosis, oliguria, or an acute alteration in mental status.

Septic shock - Sepsis-induced with hypotension despite adequate fluid resuscitation along with the presence of perfusion abnormalities that may include, but are not limited to lactic acidosis, oliguria, or an acute alteration in mental status. Patients who are receiving inotropic or vasopressor agents may not be hypotensive at the time that perfusion abnormalities are measured.

Multiple organ dysfunction syndrome-Presence of altered organ function in an acutely ill patient such that homeostasis cannot be maintained without intervention.

Adapted from Bone et al. (32).

and flawed clinical trial data (38-42). Critics were primarily dissatisfied with the inclusion of the SIRS criteria in the definition of sepsis, arguing that the criteria lacked specificity and were too sensitive to be of use in clinical diagnosis or clinical trials (41). This argument was supported by data showing that most ICU patients and many general ward patients met the SIRS criteria (43-46). Further criticism claimed that a SIRS diagnosis provided no information regarding the underlying disease process and was simply a list of clinical signs routinely seen in patients having an appropriate response to a physiologic insult. Another important criticism of the sepsis definition was that actual infection could often only be identified in $50 \%$ (or fewer) of patients who “appeared" septic $(7,44,47)$.

Given the list of complaints leveled against the 1991 ACCP/SCCM sepsis definitions, it is somewhat surprising that very few changes to the original definitions were made by the second Sepsis Definitions Conference (Table 2). The participants of the 2001 conference did concur that the SIRS criteria were too sensitive and lacked needed specificity. As a result, they created an expanded list of possible signs of systemic inflammation in response to infection (Table 3), with the caution that practitioners looking to establish a diagnosis of sepsis should only include those diagnostic criteria that cannot be easily explained by other causes. The 2001 Consensus concluded that more meaningful changes to the definition of sepsis and its associated conditions based on biomarkers were premature and that future changes to these definitions would rely on an increased understanding of-and readily available means to diagnose-the immunological and biochemical processes involved in sepsis (34).

\section{STAGING SEPSIS, MODELING EQUINE PATIENT OUTCOMES}

The concept of a clinically useful sepsis staging system was introduced by the 2001 International Sepsis Definitions Conference. The consensus stated that such a system would "stratify patients by both their risk of an adverse outcome and their potential to respond to therapy" (48). The classification
TABLE 2 | SCCM/ESISM/ACCP/ATS/SIS sepsis definitions (2001).

\section{SCCM/ESICM/ACCP/ATS/SIS sepsis definitions}

Sepsis - The presence of infection, documented or strongly suspected, with a systemic inflammatory response.

Severe sepsis - Sepsis complicated by organ dysfunction.

Septic shock-Severe sepsis complicated by acute circulatory failure characterized by persistent arterial hypotension, despite adequate volume resuscitation, and unexplained by other causes.

Multiple organ dysfunction syndrome-Presence of altered organ function in an acutely ill patient such that homeostasis cannot be maintained without intervention.

Adapted from Levy et al. (34).

TABLE 3 | SCCM/ESISM/ACCP/ATS/SIS diagnostic criteria for sepsis (2001).

SCCM/ESICM/ACCP/ATS/SIS Expanded diagnostic criteria for sepsis

Documented or suspected infection and some of the following:

General parameters:

Fever

Hypothermia

Tachycardia

Tachypnea

Altered mental status

Significant edema or positive fluid balance

Hyperglycemia (in the absence of diabetes)

Inflammatory parameters:

Leukocytosis

Leukopenia

Normal white blood cell count with $>10 \%$ immature forms

Plasma $\mathrm{C}$ reactive protein $>2 \mathrm{SD}$ above normal value

Plasma procalcitonin $>2$ SD above the normal value

Hemodynamic parameters:

Arterial hypotension

Mixed venous oxygen saturation $>70 \%$

Cardiac index $>3.51 \mathrm{~min}^{-1} \mathrm{~m}^{-2}$

Organ dysfunction parameters:

Arterial hypoxemia

Acute oliguria

Creatinine increase

Coagulation abnormalities

Ileus

Thrombocytopenia

Hyperbilirubinemia

Tissue perfusion parameters:

Hyperlactatemia

Decreased capillary refill or mottling

Adapted from Levy et al. (34).

scheme proposed for sepsis-called PIRO [Predisposition, Insult, Response, Organ failure (PIRO)]-addressed 4 major areas to stage sepsis in a manner similar to the TNM (Tumor, Lymph Nodes, Metastasis) staging system ((237)) used for oncology patients. The first component, Predisposition, addresses the growing understanding that the same insult (i.e., infection) can cause a more severe response or worse outcome in some individuals compared to others. In human medicine, the variables of "predisposition" include genetics, gender, age, and nutritional status. Clinically, this category is also recognized 
in veterinary patients. Nemzek et al. demonstrated that the white blood cells of Rottweilers and Doberman Pinschers produce a marked inflammatory cytokine response compared with that of mixed breed dogs (49). The authors correlate their findings with the predisposition of these breeds for severe infection with canine parvovirus. The concept of Predisposition is also relevant to equine patients, whose white blood cells (compared with other species) demonstrate a markedly proinflammatory response to lipopolysaccharide (LPS) $(35,50)$. Additionally, an equine experimental model shows that gene expression in LPS-stimulated peripheral blood mononuclear cells is distinctly different in some horse "families" compared to others (51). Further "predispositions" that would be interesting to investigate in terms of equine sepsis could include diseases that predispose horses to dysregulation of insulin, glucose or cortisol, such as Equine Metabolic Syndrome (EMS) or Pituitary Pars Intermedia Dysfunction (PPID). Investigators have already shown that free cortisol fraction is significantly increased in healthy overweight horses, as well as horses with PPID and insulin dysregulation (52). In a prospective observational study, Hinchcliff et al. reported that higher serum cortisol concentrations were significantly associated with increased risk of non-survival in a group of 35 adult horses presented for colic (53). While SIRS status was not reported in the Hinchcliff study, Roy et al. recently reported that SIRS at presentation was associated with increased odds of death in a group of 247 adult horses presented for colic (27), suggesting that nonsurviving horses with high cortisol in the Hinchcliff study also had SIRS. Other investigators determined that non-surviving adult hospitalized horses with SIRS had significantly decreased glucocorticoid binding affinity (54). Dysregulation of cortisol has already been associated with poorer sepsis outcomes in human patients. In a study on 164 pediatric patients, Alder et al. reported that patients with both low glucocorticoid receptor expression and high serum cortisol had higher rates $(75 \%)$ of multi-organ ( $>2$ ) failure and death (55). Taken together, this evidence suggests that previous EMS and/or PPID diagnosis could be a relevant "predisposition" for horses being treated for sepsis, and outcomes in this patient population may warrant further investigation.

The second component of the PIRO staging system addresses Insult (i.e., infection). This category conveys the importance of infection type and location, which is known to have an impact on outcome in both humans and horses (56-58). A recent publication by Declue et al. demonstrates that equine blood stimulated with components of Gram-negative and Grampositive organisms produces differing cytokine profiles (59). Other recent studies on equine sepsis in both foals and adults examine the impact of Gram-positive and mixed infections on clinicopathologic features of disease and outcomes (16, 6063). Beyond infection, "insult" could also stratify patients based on primary disease. While reported causes of "insult" leading to sepsis in adult horses include only a few causes such as pneumonia and colitis $(24,63)$, "insult" in equine neonates is highly varied and includes primary diagnoses such as ruptured bladder, pre-/dysmaturity, failure of passive transfer, neonatal isoerythrolysis, neonatal maladjustment syndrome, etc. While many studies describe blood culture as the gold standard for providing evidence of infection-related SIRS (64), other recent studies have chosen to also accept clinical evidence of infection plus SIRS as supportive of sepsis diagnosis $(15,18)$. Given the relatively low sensitivity of blood culture as used in veterinary medicine, it seems likely that blood culture as a stand-alone gold standard would lead to under-diagnosis of sepsis and that an "either/or" definition will have the most utility in the context of equine medicine (31).

The third component of the PIRO sepsis staging system is the Response to sepsis. The physical and biochemical parameters that routinely describe septic human and veterinary patients are well-known and incorporated into the currently accepted definitions of sepsis and its associated syndromes (32, 34). Unfortunately, the clinical application of these parameters (i.e., SIRS diagnosis) often fails to help clinicians gauge the severity of, or the prognosis for, an individual patient's illness; additionally, they lack sensitivity when it comes to inclusion criteria for clinical trials. Biomarkers of sepsis, in conjunction with other criteria, are increasing in their utility for diagnosing, guiding treatment and predicting outcomes for patients with sepsis (65-69). Specific biomarkers that have recently shown promise in prognosticating human sepsis include serum procalcitonin (PCT), N-terminal brain natriuretic propeptide (NT-proBNP), interleukin-6 (IL-6), prothrombin time (PT), and thrombin time (TT) $(70,71)$. Procalcitonin is also used to assist in selection of empirical antimicrobial therapy, as this biomarker has been shown to be significantly higher in patients with Gram-positive sepsis compared to Gram-negative sepsis (72, 73). Circulating biomarkers of endothelial cell dysfunction, including circulating adhesion Angiopoietin-2/Angiopoietin-1 ratio (Ang-2/Ang-1) and Angiopoietin-1/Tie-2 ratio (Ang-1/Tie2 ), intercellular adhesion molecule (ICAM)-1, vascular cell adhesion molecule (VCAM)-1 and thrombomodulin (TM), have also shown to be independent predictors of 90-day mortality in ICU patients with severe sepsis and septic shock (74). C-reactive protein is also one of the most widely studied human sepsis biomarkers, although evidence suggests that it is more useful for predicting fatal progression of septic patients rather than aiding in initial sepsis diagnosis (75). Biomarkers of inflammation and sepsis investigated in foals and adult horses include lactate, soluble CD14 (sCD14), serum amyloid A, procalcitonin, Creactive protein $(\mathrm{CRP})$, haptoglobin $(\mathrm{Hp})$, interleukin $1 \beta$ (IL$1 \beta$ ), interleukin-10 (IL-10), and interleukin-6 (IL-6) (25, 48, 76-80). In a prospective study of 643 foals, median L-lactate concentration in septic foals $(4.8 \mathrm{mmol} / \mathrm{L})$ was significantly higher than that of non-septic foals $(3.3 \mathrm{mmol} / \mathrm{L})(48)$. In 95 adult horses presented for emergency, Roy et al. report that plasma blood lactate $>2.06 \mathrm{mmol} / \mathrm{L}$ significantly increased the likelihood of death $(\mathrm{OR}=5.65 ; 95 \% \mathrm{CI}, 2.38-14.13, P<0.001)$, and lactate was included in their final outcome model of severe SIRS (27). In multiple studies, sCD14 has been shown to be elevated in either foals with septicemia (81) or adult horses classified as sick (82), or clinically endotoxemic (25); however, sCD14 has been demonstrated as a poor predictor of outcome (82). Procalcitonin, which is one of the most widely used sepsis biomarkers in human medicine, has only recently been investigated in horses. Using an 
ELISA they developed, Rieger et al. reported that mean plasma procalcitonin levels were significantly different between septic ( $n$ $=5)$ and healthy $(n=24)$ horses $(8,450 \mathrm{ng} / \mathrm{mL}$ vs. $47 \mathrm{ng} / \mathrm{mL})$ (76). In a multicenter, prospective, observational study of $<24 \mathrm{~h}$ old septic $(n=40)$, sick non-septic $(n=40)$ and $<7$ day old healthy foals, Zabrecky et al. reported that while plasma CRP increases with inflammation in neonatal foals, neither CRP or $\mathrm{Hp}$ appear to be useful as single time point biomarkers for sepsis in foals (77). Burton et al. reported that the serum IL6:IL-10 ratio could prove valuable as a prognosticator for equine neonatal septicemia (80). Using white blood cell gene expression analysis, Castagnetti et al. determined that IL- $1 \beta$ is significantly elevated in $<7$ day old sick foals with sepsis compared with non-septic sick foals and healthy foals (79). In a carbohydrate overload model of equine sepsis designed to induce laminitis, Steelman et al. used network and correlation analysis of serum metabolomics and determined that the amino acid citrulline was significantly lower in all septic study animals. As part of the same study, Steelman et al. showed that citrulline levels were significantly lower in clinical patients with adverse outcomes (i.e., laminitis or death) following presentation for sepsis or colic (6 of 19 horses) (83). Citrulline has also been identified as a potential prognostic biomarker for foals with sepsis (84). With improved sepsis definitions and agreement on relevant criterion for clinical investigations, biomarkers will undoubtedly improve the understanding, diagnosis, treatment, and even prevention, of equine sepsis.

The final component of the PIRO staging system is Organ failure. Evidence from both human and veterinary medicine indicates that evidence of organ dysfunction is an important determinant of prognosis in patients with sepsis $(29,85-$ 87). Recently, McConachie et al. developed and validated a scoring system for multiple organ dysfunction in adult horses with acute surgical colic (29). Specific criteria were measured to monitor function of the heart (serum cardiac troponin, stroke volume index, standard deviation of normal-to-normal intervals), kidneys (creatinine, $\Delta$ creatinine), liver (serum bile acids concentrations), gastrointestinal tract (nasogastric reflux volume, abdominal distension), musculoskeletal system (serum creatine kinase activity, Obel grade lameness), respiratory system ( $\mathrm{PaO} 2 / \mathrm{FiO} 2$ ratio, respiratory rate, and effort), and coagulation pathway (platelet count or prothrombin time). The neurologic system was evaluated with a modified pain score that included postural and social behaviors, demeanor, and activity. Based on laboratory reference ranges, literature review and clinical judgement, these investigators assigned each organ a score where 0 is unaffected, $1-2$ is affected and 3 is failed, yielding a maximum organ failure score of 24. Data for MODS scoring was collected on Day 1 and 2 postoperatively in 62 adult horses presented for colic and exploratory laparotomy. The MODS score generated by these criteria had a very high association with 6-month survival, and an optimal cut point of $\geq 8$ resulted in a sensitivity of $92 \%$ and a specificity of $88 \%$ for predicting survival to 6 months. Additionally, these investigators also determined that the number of organs affected $(\geq 1)$ and the number of organs failed $(=3)$ were also significantly associated with 6-month survival, and that horses with a score $\geq 8$ were 10.7 times more likely to have SIRS. Clearly, this investigation demonstrates the potential clinical utility of a MODS score for hospitalized adult horses. One potential drawback for clinical use of the proposed MODS score would be the added cost to the client for score data that is not already routinely collected, but if early identification and aggressive treatment of at-risk patients could improve patient outcomes, the benefits could ultimately outweigh the costs.

Since its inception, the PIRO concept (Table 4) has proven to be a reliable predictor of mortality in human patients with sepsis $(88,89)$. It remains to be seen whether the PIRO concept has applications in veterinary medicine.

\section{DEFINITIONS OF SIRS IN EQUINE MEDICINE}

While numerous equine studies have utilized the consensus definitions of SIRS and sepsis proposed by human medicine, there is ongoing debate on how to best define these terms for equine veterinary medicine. Consequently, veterinary researchers have directed significant efforts toward developing and interrogating various SIRS/sepsis scores and models to aid clinicians in predicting patient outcomes.

\section{SIRS Criteria in Neonates/Foal}

In a recent review of equine neonatal sepsis, Wong et al. (90) present criteria for SIRS diagnosis based on the presence of 3 of 6 criteria (fever or hypothermia, tachycardia, tachypnea, leukocytosis, or leukopenia, hyperlactatemia, hypoglycemia) tailored to 4 different age categories (newborn, neonate, juvenile, weanling) (90). Wong et al. further stipulate that, as in human pediatrics (91), at least 1 of the criteria must be abnormal temperature or leukocyte count due to the fact that diseases affecting neonates often cause tachycardia and tachypnea. In a subsequent paper, Wong et al. use their neonatal SIRS criteria to create what they called an "updated" sepsis score (14), which they based on the "modified equine neonatal sepsis score" published in 1988 (92). In addition to adding the neonatal SIRS criteria, the updated sepsis score also incorporated blood L-lactate, serum creatinine and lymphocyte count. Using a prospective study design, the investigators collected historical, physical examination, and clinicopathologic findings on 273 sick foals ( $<30$ days old) presented to six different veterinary referral centers to compare the association of original and updated equine neonatal sepsis and SIRS criteria with sepsis in foals. Foals were classified as septic if they had any one of the following: (1) positive blood culture, (2) $>1$ site of infection based on cytology, bacterial culture, or histopathology, or (3) postmortem evidence of $>1$ septic process, as previously described (15). The "updated" sepsis score did not improve the ability to predict sepsis over the modified sepsis score, and the modified SIRS criteria was slightly better at predicting sepsis (more significant OR) than the equine neonatal SIRS criteria (14). In another recent report, Weber et al. conducted a retrospective cohort study on hospital records of equine neonates admitted to a veterinary teaching hospital between 1982 and 2008. Data collected from these records were 
TABLE 4 | P I R O (sepsis patient staging system).

\begin{tabular}{|c|c|c|c|c|}
\hline & $\begin{array}{l}\text { P } \\
\text { Predisposition }\end{array}$ & Infection & $\begin{array}{l}\text { R } \\
\text { Response }\end{array}$ & $\begin{array}{l}\text { O } \\
\text { Organ dysfunction }\end{array}$ \\
\hline Available & $\begin{array}{l}\text { Age } \\
\text { Comorbidities } \\
\text { Chronic Conditions } \\
\text { Baseline severity } \\
\text { Source of admission }\end{array}$ & $\begin{array}{l}\text { Pathogen } \\
\text { Susceptibility } \\
\text { Bacteremia } \\
\text { Bacterial load } \\
\text { Site of infection } \\
\text { Nosocominal or community-acquired }\end{array}$ & $\begin{array}{l}\text { Clinical resolution } \\
\text { Hypoxemia } \\
\text { Hypotension } \\
\text { Immune response }\end{array}$ & $\begin{array}{l}\text { ARDS } \\
\text { Shock } \\
\text { Acute renal failure } \\
\text { MODS } \\
\text { SOFA }\end{array}$ \\
\hline
\end{tabular}

Adapted from Levy et al. (34).

used to evaluate performance of the "modified sepsis score" (93), to determine whether sepsis scores change significantly over time and to determine objective clinical factors associated with sepsis. Using data from 1065 foals, Weber et al. showed that the modified sepsis score was significantly better at predicting sepsis than a multivariable model generated from objective criteria. They also show that diagnostic performance of the modified sepsis score did not change significantly over time, and that the sensitivity of the modified sepsis score in this patient population was improved by decreasing the cut point from $>11$ to $>7$ (15).

\section{SIRS Criteria in Adult Horses}

While several studies have examined SIRS and sepsis criteria in equine neonates, there is only one recent study on SIRS in adult horses. In 2017, Roy et al. conducted a prospective observational study to determine the prognostic value of measures of SIRS in adult horses presented for emergency treatment and to identify the best model of severe SIRS to predict outcome. In this study, SIRS criteria included the following: heart rate $>52 \mathrm{bpm}$, respiratory rate $>20 \mathrm{bpm}$, temperature outside the range of $37.0-38.5^{\circ} \mathrm{C}$ and $\mathrm{WBC}$ count outside the ranges of $5.0-12.5$ $\times 10^{9} / \mathrm{L}$. Using these criteria, Roy et al. reported that $31 \%$ of 464 emergency cases had 2 or more abnormal SIRS criteria at admission and that SIRS diagnosis was associated with increased odds of death. They also reported that horses with 3 and 4 signs of SIRS (SIRS3/4) had increased odds of death compared to non-SIRS cases $(\mathrm{OR}=19.80 ; 95 \% \mathrm{CI}, 9.18-42.74, \mathrm{P}<$ 0.001 ) or the horses with just 2 signs of SIRS (SIRS2) (OR $=4.45 ; 95 \% \mathrm{CI}, 1.78-11.15 ; P=0.002$ ). Additionally, they determined that a model of severe SIRS, including SIRS score and markers of tissue perfusion (blood lactate concentration $>2.06 \mathrm{mmol} / \mathrm{L}$ and altered mucus membrane color), generated the best model for predicting outcome in this population of horses (27).

\section{MECHANISMS OF HOST DEFENSE-PATHOPHYSIOLOGY OF SEPSIS}

\section{Local Inflammation}

The four cardinal signs of inflammation (as described in the 1st century AD) are rubor et tumor cum calore et dolore (94). This translates to redness and swelling with heat and pain. In today's terms, we explain these ancient observations with the modern terms of peripheral vasodilation (redness), vascular leakage (swelling), and fever (heat). We now understand that these concepts, recognized by the Ancient Greeks Galen and Celsus, are essential to local host defense from invading microorganisms. Within the environment, plants, and animals are exposed to potentially invasive microorganisms, and as such are armed with defensive mechanisms. In mammals, the first line of defense is the physical barrier, including skin and mucous membranes, mucous layers that line the respiratory and gastrointestinal tracts, various enzymes, and antimicrobial peptides. These barriers repel the vast majority of microorganisms, but when pathogens do "breach the wall," vasodilation and vascular leakage, mediated by the local release of tumor necrosis factor- $\alpha$ (TNF $\alpha)$, interleukin (IL)-1 $\beta$ and histamine, promotes the recruitment of professional phagocytes (i.e., neutrophils) to the area (95). Armed with bactericidal and proteolytic enzymes, as well as the ability to produce reactive oxygen intermediates, neutrophils are uniquely suited for killing pathogens. Additionally, local activation of the coagulation cascade slows the dissemination of the infectious organisms through the formation of microthrombi, which occlude small vessels. Ultimately, the goal of these defense mechanisms is to eliminate the pathogen locally, at the site of invasion. Sepsis occurs when the host response to infection becomes systemic. This systemic response has detrimental effects on tissues and organ systems remote from the site of initial injury (96). The pathophysiology of this process is extremely complex.

\section{Pathogen Recognition-A Key Component of Host Defense}

In vertebrates, there are two arms to the immune system: innate and adaptive immunity. The innate immune system was the first to evolve, and as such is present in all plants and animals, while adaptive immunity is found only in vertebrates. Both components of the vertebrate immune system have unique features that are vital for optimal host defense. The innate immune response is capable of instantaneous pathogen recognition and rapid mobilization of destructive cellular forces, but it is incapable of providing long-term immunity, which is the responsibility of the slower-responding adaptive immune system. 


\section{Triggers and Receptors of the Innate Immune Response}

Key molecules involved in the immune system recognition of pathogens and tissue injury are pathogen-associated molecular patterns (PAMPs) and damage-associated molecular patterns (DAMPs, also "alarmins"), respectively. The list of PAMPs includes LPS, flagellin, peptidoglycan, lipoteichoic acid, double stranded viral DNA, and unmethylated CpG motifs (97). Molecules that act as DAMPs include hyaluronan, heparan sulfate, heat shock proteins, high mobility group protein B1 (HMGB1) and adenosine triphosphate (ATP) (98). While DAMPs have received recent attention as models of sterile inflammation, both PAMPs and DAMPs are relevant to the discussion of sepsis pathophysiology. The hallmark of clinical sepsis is a harmful or damaging host response to infection. While it is accepted that PAMPs are involved in the initiation of the inflammatory response, it is reasonable to suspect that tissue injury caused by invading pathogens and/or the host (i.e., neutrophil mediated damage) would also generate DAMPs. DAMPs could then further activate the innate immune response, leading to additional inflammatory cytokine signaling, neutrophil recruitment, and tissue damage. Considering the cross-reactivity of individual pattern recognition receptors (PRRs) for PAMPs and DAMPs (98-100), a vicious cycle of signal amplification ultimately results in a globally dysregulated immune response. Evidence shows that interaction of PAMPs and DAMPs with their receptors is correlated with increased rates of fatality in a polymicrobial mouse model of sepsis (101). Although at present the consequences of this amplification cycle in veterinary species is only inferred, cross-reactivity of equine PRRs with different DAMPs and PAMPs has been demonstrated $(59,102)$.

The PAMPs and/or DAMPs present in inflamed and/or infected tissues are recognized by signaling PRRs on the surface of immune cells such as neutrophils, macrophages, mast cells, and dendritic cells, and non-immune cells such as epithelial cells, endothelial cells, myocytes, and fibroblasts (100, 103, 104). There are numerous types of PRRs, including leucine-rich repeat-containing proteins (NLRs, previously called NOD-like receptors), C-type lectin receptors (CLRs), RIG-I-like receptors (RLRs), and Toll-like receptors (TLRs) (105). TLR signaling is an essential step in the activation of the innate immune response. TLRs are needed for the clearance of bacterial infection, but excessive TLR signaling can lead to systemic inflammation, which can have detrimental consequences to the host. Because of the relative importance of endotoxin in a number of equine diseases, Toll-like receptor 4 (TLR4), which binds the lipid A component of LPS, has been the subject of much research and will be further discussed. Other members of the TLR family identified in horses (TLR 2, 3, 5, 8, and 9) are reviewed in detail elsewhere $(35,97,106)$.

In order to bind TLR4, LPS must first interact with LPSbinding protein to then bind either soluble or membranebound (myeloid cells) CD14 (107, 108). After CD14 binding, LPS interacts with TLR4 and its co-receptor MD-2, which results in TLR/interleukin (IL)-1 receptor-associated protein (TIRAP)-dependent recruitment of the MyD88 adaptor protein
(109). MyD88 activation causes activation of the transcription factor NF-kB as well as phosphorylation of mitogen-activated protein kinases (MAPK). The most well-recognized and frequently reported result of TLR4-LPS binding is NF- $\mathrm{KB}$ mediated upregulation of pro-inflammatory mediators such as TNF $\alpha$ and IL-1 $\beta$. However, LPS-mediated TLR 4 activation on circulating monocytes in some species induces simultaneous upregulation of IL-10 and IL-1R $\alpha$ genes, showing that TLR4 signaling also activates anti-inflammatory mediators (110). This two-pronged activation of pro- and anti-inflammatory mediators serves to rapidly clear infection while limiting the overall level of immune system activation; however, this coordinated activation of pro- and anti-inflammatory mediators by TLR 4 in humans is somewhat different in the horse (35).

Based on differences in equine TLR4-LPS signaling, the equine monocyte response to LPS is more pro-inflammatory than that of other species. The primary cause of this difference is that LPS-activation of TLR4 primarily signals through MyD88, with minimal activation of TRIF-mediated gene expression, as demonstrated in experiments with equine monocytes (50). As a result of MyD88 signaling, LPS stimulation of equine monocytes elicits a rapid and short-lived induction of TNF $\alpha$ mRNA, a rapid and more sustained expression of IL- $1 \beta$ mRNA, and slower but sustained induction of IL-6 mRNA. After an approximately 4$\mathrm{h}$ delay, IL-10 mRNA expression is also induced, although the level of induction is much lower than that seen with TLR3 agonists such as double stranded viral DNA. The result is stronger signaling from the MyD88 pathway, which is regarded as proinflammatory, and diminished signaling from the TRIF pathway, which is considered anti-inflammatory. In other species, $\mathrm{PI}(3) \mathrm{K} \delta$ regulates the switch in TLR4 signaling between MyD88 and TRIF, but this event does not seem to occur in equine monocytes. These attributes of TLR4 signaling specific for equine monocytes, taken together with their remarkable sensitivity to " $\mathrm{nM}$ " concentrations of LPS, provide a scientific basis for the marked inflammatory response that horses experience in response to endotoxin exposure (50).

\section{Cytokines in Sepsis}

The focus of early human sepsis research was the SIRS, which was believed to be an overwhelming and unchecked spike in the host's pro-inflammatory immune response (96). Although SIRS can occur in response to trauma, anaphylaxis, ischemia, hemorrhage, and sterile inflammation (i.e., pancreatitis), in the case of sepsis the inciting event is documented or suspected infection. High levels of circulating pro-inflammatory cytokines, such as TNF $\alpha$, IL-1, and interleukin-6 (IL-6), were cited as evidence of SIRS in both septic human patients and laboratory animals with induced sepsis. The belief that sepsis was a state of hyper-inflammation led to numerous clinical trials investigating agents that would block, neutralize, remove, or attenuate various pro-inflammatory mediators. As the majority of these studies failed, the proposed hyper-inflammatory pathogenesis of sepsis was re-examined. At that time, based on new evidence of immunosuppression/immunoparalysis in septic patients (111), it was proposed that SIRS was only the initial phase of sepsis followed by a compensatory anti-inflammatory response 
syndrome (CARS), leading to adverse events such as increased rate of nosocomial infections (96). Hallmark characteristics of CARS were cited as diminished expression of major histocompatibility complex class II molecules on circulating monocytes (mHLA- DR), massive apoptosis of circulating lymphocytes and elevated plasma levels of the anti-inflammatory cytokine IL-10 (112). This notion of a multi-modal or twophase inflammatory response to sepsis has since been rejected and replaced by evidence of an integrated, highly mixed antiinflammatory response syndrome (MARS) (113).

The cytokine features of equine sepsis and critical illness are currently the subject of intense study. At this time, much of the inflammatory cytokine data available is based on models of equine sepsis, such as intravenous LPS infusion or oral administration of black walnut extract (BWE) or carbohydrate. Evidence from these models shows that, as in other species, horses initially produce TNF $\alpha$ in response to LPS (114-116). High levels of circulating $\mathrm{TNF} \alpha$ are also present in horses with colic, a disease that often elicits a systemic inflammatory response. Further, marked increases in TNF $\alpha$ have been linked to a higher rate of mortality in cases of equine colic and sepsis in foals $(117,118)$. TNF $\alpha$ is known to induce the expression of interleukin (IL)-1 $\beta$, and administration of these two cytokines together is enough to reproduce septic shock in animals (119, $120)$. In horses, IL-1 $\beta$ elevations have been documented in foals with naturally occurring sepsis and in adult horses following LPS infusion $(79,121)$.

Another important cytokine during sepsis in humans and horses is IL-6, which is produced after cells are exposed to TNF $\alpha$ and IL- $1 \beta$. While IL- 6 is not considered to be a pro-inflammatory cytokine, neither is it considered anti-inflammatory. LPS infusion in adult horses causes a significant increase in circulating levels of IL-6 (121). In one report on neonatal foals with naturally occurring sepsis, IL-6 levels were lower than healthy agematched controls (80). These investigators provide evidence that healthy foals acquire a significant amount of IL- 6 from the passive transfer of immunity. In a different report, IL-6 gene expression was significantly increased in non-surviving septic foals compared to foals that survived sepsis (122). Because these two studies examined either IL-6 protein or mRNA, but not both, their apparently conflicting results are difficult to resolve. In human sepsis trials, persistently elevated levels of IL-6 correlated with disease severity and an increased risk of death (111). However, in foals evidence suggests that IL-6 protein is lower in the blood of septic vs. healthy foals and that the IL6:IL10 ratio, which was higher in the healthy age matched foals compared to septic foals, may be a useful prognostic indicator for neonatal septicemia (80).

The most commonly investigated anti-inflammatory cytokine in people and horses is IL-10, although other anti-inflammatory mediators include IL-4, IL-11, IL-13, transforming growth factor $\beta$, soluble TNF receptors and IL-1 receptor antagonist $(87,123)$. Anti-inflammatory cytokines offer a counterbalance to the proinflammatory signals, resulting in suppressed production of IL$1 \beta, \mathrm{TNF} \alpha$ and chemokines and decreasing vascular adhesion molecules. Increased levels of IL-10 in human patients with sepsis is associated with poorer outcomes and an increased risk of MODS and death (124-126). In equine neonatal sepsis, significantly elevated levels of IL-10 have been reported in nonsurvivors compared to survivors (122). However, another study compared levels of circulating IL-10 between septic foals and healthy controls and found no difference (80). Whether or not IL-10 levels correlate with outcome in adult equine patients with naturally occurring sepsis has yet to be investigated.

\section{NEUTROPHILS IN HEALTH AND SEPSIS}

In 1882, Elie Metchnikoff observed recruitment of phagocytic cells to sites of injury in starfish embryos and hypothesized that they (i.e., neutrophils) were involved in microbe digestion (127). This observation began more than a century of research that continues to examine the role of neutrophils in host defense, host injury, microbial killing, resolution of inflammation, immunodeficiency and tissue healing. The goal of this section of the review is to cover broad topics of neutrophil physiology that are relevant to the pathophysiology of sepsis; the reader is referred elsewhere for details regarding the molecular mechanisms of sepsis and a more detailed examination of neutrophil signaling $(10,128)$.

\section{The First Responder}

Neutrophils are essential for host defense against bacteria. Patients that are neutropenic or have leukocyte adhesion deficiency are at increased risk for bacterial infection (129). On the other hand, neutrophil effector functions, such as release of reactive oxygen species (ROS) and extracellular traps (NETs), can be very damaging to host tissue in a number of diseases including sepsis. Therefore, neutrophils are potential targets for combating sepsis-associated organ damage. A better understanding of neutrophil functions and molecular regulators of neutrophil responses could lead to novel targets for therapeutic modulation of neutrophil dysfunction in sepsis.

There are several key features of neutrophils that make them particularly effective at responding to bacterial invasion. (1) Neutrophils are the most abundant leukocyte in systemic circulation, with $2.9-8.5 \times 10^{9}$ cells/l circulating in healthy adult horses, and 2.5-7.5 $\times 10^{9}$ cells/l in adult humans. Importantly, these circulating neutrophils are maintained in a quiescent state until they receive signals for recruitment and activation. This is an important safety mechanism that normally keeps the destructive power of neutrophils in check. (2) Large numbers of neutrophils are rapidly recruited to circulation from the reserves of neutrophils located in the bone marrow. This is particularly important, considering the lifespan of terminally differentiated neutrophils is assumed to be relatively short (i.e., half-life of $10.5 \mathrm{~h}$ in the horse and $8 \mathrm{~h}$ in humans) (130-132), although recent evidence that the average neutrophil lifespan is 5.4 days has cast doubt on that assumption (133). (3) Under physiologic conditions, neutrophils are found both in circulation as well as in marginated pools in the spleen, liver and lung $(134,135)$. Although the reason for the concentration of neutrophils in these organs remains uncertain, it is postulated that organ-neutrophils are acting as sentinels, providing constant surveillance for the detection of, and defense against, microbial 
invasion, and tissue damage. (4) In response to chemotactic stimuli, neutrophils can migrate at extremely fast velocities (up to $12 \mathrm{um} / \mathrm{min}$ ), meaning they have a tissue target response time as short as $3 \mathrm{~h}$ after initial insult. (5) Neutrophils are equipped with a remarkable contingent of surface receptors and adhesion molecules that facilitate activation and endothelial transmigration and culminate in the arrival of neutrophils at remote sites of tissue injury or infection. All these properties make neutrophils uniquely suited to provide a rapid response to bacterial invasion in the host.

\section{Neutrophil Recruitment}

Damage to tissues, whether the result of sterile injury or pathogenic invasion, is recognized by immune cells such as macrophages and mast cells as well as by stromal cells (136-138). Characteristic stimuli, including PAMPs and DAMPs, activate these cells to release pro-inflammatory mediators such as IL- $1 \beta$ and TNF $\alpha$ as well as chemoattractants for neutrophils $(139,140)$. The local release of these mediators causes the neighboring vascular endothelium to increase endothelial expression of P-selectin and then later E-selectin and ICAM-1 (141-143). Neutrophils passing the area of activated endothelium enter a reversible adhesion cascade that consists of six steps, mediated by specific ligand-receptor interactions and molecular mechanisms. The initial steps of the leukocyte adhesion cascade are capture and rolling. They are mediated by induced endothelial expression of P- and E-selectin and neutrophil-expressed L-selectins and Eselectin ligand (ESL-1), P-selectin ligand (PSGL-1) and CD44, which are expressed constitutively $(144,145)$. The strength of these selectin-mediated attachments only develops during the shear stress that neutrophils experience during laminar blood flow $(146,147)$. Also important for the progression of neutrophil adhesion to the blood vessel wall is the presentation of endothelial-bound chemokines to their respective G-protein coupled receptors (GPCRs) on the neutrophil cell surface. GPCR signaling leads to "inside-out" activation of neutrophil $\beta 2$ integrins (148). This activation of neutrophil $\beta 2$-integrins Mac-1 (CD11b, $\alpha \mathrm{M} \beta 2$ ) and LFA-1 (CD11a, $\alpha \mathrm{L} \beta 2)$ facilitates adhesion to their respective ligands on the endothelial surface-ICAM-1 and ICAM-2-which leads to $\beta 2$-intgerin "outside-in" activation and subsequent slow rolling, arrest, and finally adhesion strengthening. Following adhesion strengthening, neutrophils physically prepare for their transendothelial journey, taking on a characteristic polarized appearance with a leading edge lamellipodium and a trailing edge uropod (149). Using $\beta 2$ integrin-dependent mechanisms, reviewed in detail elsewhere (150), neutrophils traverse the endothelium via transcellular or paracellular routes, cross the basement membrane and home in on sites of bacterial invasion.

\section{Chemotaxis}

Circulating neutrophils, initially distant from the primary site of pathogen invasion, are recruited to the area of tissue infection by an uncontested gradient of endogenously produced host chemokines (i.e., interleukin-8 and leukotriene-B4) known as intermediate chemoattractants. As neutrophils cross the endothelium to enter the actual site of infection, they must "ignore" the chemokine gradients of diffusely inflamed host tissue in order to "target" invading microorganisms. Endstage chemoattractants derived from bacterial peptides and host complement factors, such as N-Formyl-methionyl-leucylphenylalanine (fMLP) and C5a, signal neutrophils to converge at the point of bacterial invasion in order to phagocytose foreign material and release their arsenal of antimicrobial agents including oxidants, proteinases, and cationic peptides (147).

Chemoattractant receptors play a vital role in translating the spatial cues of the chemoattractant gradient to the cellular machinery that drives neutrophil locomotion. Neutrophils "sense" these chemoattractant gradients by virtue of independent GPCRs and "prioritize" intermediate and end-stage chemoattractant signals using the phosphatidylinositol-3-OH kinase $(\mathrm{PI}(3) \mathrm{K})$ and tensin homolog (PTEN) pathway and the p38 MAPK pathway, respectively $(151,152)$. With damage to the machinery of migration (as occurs in sepsis), neutrophils lose their "compass," fail to control infection and become a liability to their host.

\section{Abnormal Neutrophil Numbers in Sepsis}

Altered numbers of circulating white blood cells are a defining characteristic of SIRS and sepsis (32). As the most abundant white blood cell in circulation, neutrophils play a significant role in determining whether patient WBC counts fall outside a normal reference range. During LPS infusion models of SIRS, circulating neutrophil numbers in adult horses fall significantly within the first 2-4h (neutropenia) and then rebound to increased numbers (neutrophilia) $(153,154)$. Blood neutrophils are also significantly increased $18-20 \mathrm{~h}$ after oligofructose-induced colitis in adult horses (155). Changes in numbers of circulating neutrophils during SIRS and sepsis are attributed to mobilization signals from cytokines, bacterial products and other inflammatory mediators (156). Additionally, under these conditions the life span of neutrophils is altered. In healthy states, neutrophils are removed from circulation following intrinsic activation of apoptosis and macrophage phagocytosis in the spleen, liver and bone marrow (157); but in human neutrophils exposed to bacterial LPS (158) or neutrophils from patients with sepsis (159), apoptosis is delayed. This is also true in horses. Horses with strangulating intestinal lesions have a lower proportion of circulating apoptotic neutrophils than horses that underwent surgical arthroscopy (160). Recent investigations also show that induced oligofructose colitis in horses, which causes severe diarrhea and SIRS, results in a significant delay in neutrophil apoptosis ex vivo. These investigators went on to show that LPS treatment delays apoptosis of equine neutrophils in vitro in a dose-dependent manner (161), and that delayed apoptosis is attributed to caspase- 9 activity but not caspase- 3 or caspase8 (161). These authors propose that the prolonged life span of neutrophils in endotoxemic horses may contribute to the development of SIRS.

Numbers of immature, or band, neutrophils are also altered during sepsis, and increase in these cells is known as a "left shift." A "left shift" is significant because compared to mature neutrophils, immature neutrophils have a relatively longer life span and are resistant to spontaneous apoptosis, have higher 
basal levels of pro-inflammatory mediators compared to antiinflammatory mediators (i.e., TNF $\alpha / \mathrm{IL}-10$ ratio), demonstrate reduced migration in response to chemoattractants, produce less ROS, and have decreased phagocytic and bactericidal activity $(162,163)$. An increase in the percentage of immature granulocytes (IG) is a marker of severe infection (164), has been associated with sepsis diagnosis (165) and is associated with mortality in neonatal sepsis (166). A recent prospective, observational study shows that in human ICU patients, total IG count discriminates between infected and non-infected patients with a sensitivity of $89.2 \%$ and a specificity of $76.4 \%$ in the first $48 \mathrm{~h}$ of SIRS. Additionally, IG count was more indicative of infection than other biomarkers including Creactive protein, lipopolysaccharide binding protein (LBP) and IL-6. The IG count was not, however, a good prognostic marker for mortality in this patient population (167). Similar results were reported for the delta neutrophil index (DNI), an automated estimate of IG count, in septic dogs (168). DNI was significantly higher in dogs with sepsis compared to dogs with immune-mediated hemolytic anemia (IMHA) and healthy dogs and significantly higher in dogs with septic shock compared to septic dogs without circulatory failure; however, no differences were detected between survivors and non-survivors (168). In a recent prospective observational study of adult equine emergency patients, the presence of band neutrophils on blood smear at admission was associated with SIRS and with poor outcome (28). Mean number of band neutrophils was also significantly increased in horses with strangulating intestinal lesions compared with control horses (169) and in neonatal foals diagnosed with sepsis (170). The association of automated IG count with SIRS severity, sepsis and outcome has not been investigated in horses.

\section{Altered Neutrophil Rigidity and Capillary Bed Sequestration}

During healthy conditions, normal neutrophils with a diameter of $\sim 7-9 \mu \mathrm{m}$ deform in order to pass through capillaries with an average diameter of $5-6 \mu \mathrm{m}$. In human patients with sepsis, neutrophil deformability is decreased, and neutrophils trapped in the capillary beds alter blood flow and release oxygen radicals and proteases that contribute to organ damage (171). In vitro studies have shown that decreased neutrophil deformability in response to $\mathrm{fMLP}$ or $\mathrm{TNF} \alpha$ is associated with the appearance of a submembrane ring of F-actin (172). It has been reported that neutrophil rigidity increases proportionally with sepsis severity (173) and that this leads to an accumulation of neutrophils in the capillary beds of lung and liver sinusoids. In a rat model of bacterial pneumonia, neutrophils with submembrane F-actin were preferentially retained over neutrophils without F-actin during passage through the lungs (174). Decreased neutrophil deformability has also been detected in LPS-stimulated equine neutrophils (175) as well as in equine patients with conditions that cause SIRS, including colic due to inflammatory bowel disease and intestinal strangulation (169). In horses with intestinal strangulation, changes in neutrophil deformability, along with size, and granularity, were correlated with poor outcome (169). It is unknown whether alterations in actin structure contribute to neutrophil accumulation within the laminae, or other organs, of horses with sepsis.

\section{Altered Neutrophil Migration}

The neutrophil's response to inflammation is mediated in large part by chemokines and cytokines, which signal neutrophils through GPCRs. During sepsis, the expression of these neutrophil agonists can be aberrantly increased. This can reduce neutrophil responsiveness in at least two ways. With a high rate of ligand binding, GPCRs are functionally desensitized due to a lack of gradient sensing ability (176). Additionally, GPCRligand binding leads to receptor internalization, which also effectively blunts GPCR-mediated neutrophil activation. These mechanisms are recognized clinically in septic patients, whose neutrophils have decreased surface expression of CXCR2 (also known as the IL-8 receptor) (177). In mice, sepsis has also been shown to upregulate the CCR2 chemokine receptor (178). The result of this upregulation is an increase in random neutrophil migration, an accumulation of neutrophils in remote organs and a failure of neutrophils to accumulate at the focus of infection. In this study, genetic, or pharmacologic inhibition of CCR2 protected mice from mortality in a cecal ligation puncture (CLP) sepsis model. In contrast to the lack of CXCR2 function that impacts neutrophil function during sepsis, the effects of CCR2 were associated with increased function, demonstrated by the finding that severity of patient illness correlated positively with increasing neutrophil chemotaxis to CCR2 ligands. The authors conclude that CCR2 may help drive the inappropriate infiltration of neutrophils into remote organs during sepsis. Interestingly, the altered expression patterns and functions of CXCR2 and CCR2 seen during sepsis are driven by TLR activation in neutrophils $(178,179)$. It is likely that both of these alterations in GPCRmediated neutrophil function are contributing to dysfunctional migration of neutrophils during sepsis.

Evidence suggests that increased circulating levels of cytokines and chemokines may hinder normal neutrophil recruitment from the vasculature. Patients with sepsis frequently have elevated levels of IL-8, C5a, and TNF $\alpha$ in their blood (180). Elevated levels of TNF $\alpha$ have also been documented in foals with presumed "septicemia" (118). In vitro, IL-8 pretreatment led to reduced neutrophil migration across endothelial monolayers (181), and in vitro exposure of neutrophils to C5a concentrations comparable to those in the blood of septic patients completely paralyzed the neutrophil migrational response $(112,182)$. Elevated $\mathrm{TNF} \alpha$ in the blood of septic patients decreases neutrophil migration, inhibits neutrophil apoptosis, enhances neutrophil priming, and production of reactive oxygen species and suppresses neutrophil CXCR2 expression $(158,183,184)$. In in vitro studies, Brooks et al. showed that the chemoattractant IL- 8 is able to attenuate migration of equine neutrophils to platelet-activating factor (PAF) and, to a lesser extent, LTB4, in a CXCL2-dependent manner. These authors conclude that this effect could lead to trapping of activated neutrophils at sites of inflammation in vivo (185). The increased presence of primed neutrophils within the vasculature, which has been demonstrated in septic patients, 
may extend neutrophil-endothelial interactions and ultimately contribute to vascular and organ damage.

\section{Altered Effector Functions}

In order to combat pathogens, neutrophils produce inflammatory cytokines and chemokines, generate reactive oxygen species, phagocytose pathogens and release NETs (186188). In neutrophils from septic patients, all these functions can be altered, but the extent of these alterations, as well as whether the functions are enhanced or suppressed, varies depending on the sepsis model being studied, the timing and the individual patient.

In one recent study, Tang et al. used microarray analysis to profile the gene-expression of neutrophils collected from septic patients within $24 \mathrm{~h}$ of hospital admission (189). These results document the downregulation of inflammatory response genes, immune modulation genes, and genes required for oxidant production. This is consistent with evidence of progressive impairment of oxidant production in murine neutrophils during Pseudomonas sepsis (190) and the impaired neutrophil phagocytic activity that has been correlated with poor outcomes in patients with sepsis (191). However, the dampening of neutrophil effector functions at the gene expression level is not indicative of complete immunosuppression because peripheral blood leukocytes from septic patients have substantial induction of several antimicrobial genes (186). It has been suggested that this divergence in the regulation of host defense genes is supportive evidence for reprogramming of neutrophil effector functions during sepsis.

The evidence for altered neutrophil phagocytosis during sepsis is variable. On one hand, human patients with severe sepsis and poor outcomes had decreased neutrophil phagocytic activity within the initial $24 \mathrm{~h}$ of hospital admission (191). On the other hand, neutrophils from septic patients show enhanced internalization and destruction of microorganisms, and neutrophils from septic foals do not differ significantly from healthy foals in phagocytic ability (192). Unfortunately, intact phagocytic function is not helpful if neutrophils fail to arrive at the focus of infection, and several different animal studies have shown that a lack of neutrophil migration into infectious sites is associated with reduced survival (176). In addition to the blunting of neutrophil chemotaxis seen with excess levels of circulating chemotactic mediators, researchers also attribute this failure of migration to decreased rolling and adhesion of neutrophils to endothelium, observed during CLP sepsis in mice (193). On the surface, it would seem difficult to resolve this observation with the evidence that neutrophil accumulation in tissue is contributing to sepsis-associated organ injury (i.e., MODS, laminitis). Clearly, when it comes to altered neutrophil migration during sepsis, the multiple mechanisms that differentially affect the neutrophil's ability to traverse the endothelium are likely impacted by the proximity of that endothelium to sites of infection and specific organs.

In order to destroy invading microorganisms, activated neutrophils produce ROS such as superoxide $\left(\mathrm{O}_{2}-\right)$ through a process known as respiratory burst. In order to generate and release ROS, neutrophils must assemble a five-subunit enzyme complex known as NADPH at either the phagosome or plasma membrane. Within the resting neutrophil, three of the subunits (p40PHOX, p47PHOX, and p67PHOX) are consistently present within the cytosol, while the other two components (p22PHOX and gp91PHOX) are located within the membranes of the secretory vesicles and specific granules. It is only when neutrophils are fully activated that the components assemble and ROS are released. This is an important protective mechanism for the host, as the release of ROS can damage not only microorganisms but also host tissue. This is true in septic patients, whose neutrophils have an enhanced ability to generate reactive oxygen species compared to healthy people, and whose plasma has been shown to cause ROS generation by human umbilical vein endothelial cells, which has been correlated with organ dysfunction and mortality. Increased neutrophil ROS generation detected in septic patients on day 0 is decreased in survivors by day 7 , whereas it remains elevated in nonsurvivors (194).

Neutrophil extracellular traps are the most recently discovered tool in the neutrophil's arsenal of host defense mechanisms (195). NETs are formed when elastase, released from azurophlic granules, causes decondensation of nuclear chromatin, which is then extruded (along with histones, myeloperoxidase, neutrophil elastase, cathepsin G, and antimicrobial proteins) extracellularly. NETs are released from neutrophils in response to cytokines (i.e., IL-8), microbial components (i.e., LPS), phorbol esters (i.e., PMA), and activated platelets and endothelial cells. NETs enhance neutrophil bacterial killing by physically capturing bacteria and bringing them into close proximity with antimicrobial proteins. Indeed, the effectiveness of NETs in killing a wide variety of Gram-positive and Gram-negative bacteria, as well as fungi (Candida albicans) and protozoa (Leishmania amazonensis), has been demonstrated both in vivo and under flow conditions in vitro (196). While NETs are clearly beneficial for host defense, widespread release of NETs may have a role in organ injury during sepsis (197). In various studies, NETs have been shown to contribute to hepatocellular injury, damage endothelial cells and instigate fibrin deposition and thrombus formation $(198,199)$. An indirect measure of neutrophil NETs in systemic circulation is plasma cell-free DNA (cfDNA). In a CLP mouse model, and in naturally occurring pediatric and canine sepsis, the ratio of cfDNA to neutrophils is increased with sepsis (200-202). A recent human prospective observational cohort study determined that ex vivo neutrophil NETosis was impaired in patients with severe sepsis compared to septic patients and controls and that reduced NETosis ex vivo was associated with poorer outcomes in septic patients (203). To date, investigations of NETosis of equine neutrophils has been limited to reproductive and respiratory research (204-208). The importance of NETs in equine sepsis pathophysiology, diagnosis, and treatment remains to be determined.

\section{Neutrophil Mediated Organ Damage}

After the successful elimination of bacteria, neutrophils undergo apoptosis, or programmed cell death (209), but during sepsis, neutrophil apoptosis is delayed (see previous). This may contribute to the accumulation of neutrophils in the organs of patients with sepsis, an occurrence that is commonly 
documented in animal models of sepsis as well as during autopsies of human patients that died as a result of sepsisinduced multiple organ failure $(210,211)$. In humans with sepsismediated organ dysfunction, the lungs are the most common organ to undergo remote or secondary injury (212). This complication is referred to as acute lung injury (ALI) or acute respiratory distress syndrome (ARDS). Among the key players in the pathophysiology of ALI/ARDS, neutrophils are considered to have a crucial role in disease progression and outcome (213). During the initial exudative phase of ALI and ARDS, several pro-inflammatory mediators (i.e., IL-8) initiate migration and pulmonary infiltration of neutrophils into the interstitial tissue, where they cause injury and breakdown of the pulmonary parenchyma. In patients with ARDS, the concentration of IL8 and the concentration of neutrophils in the bronchoalveolar lavage (BAL) fluid correlate with ARDS severity and outcome (214), and severity of lung injury can be reduced by neutrophil depletion in mice (215).

In both neonatal and adult horses, naturally occurring, and experimentally induced systemic inflammation and/or sepsis has been associated with increased neutrophil accumulation in target organs and/or multiple organ dysfunction. Reports of organs affected include the lungs, heart, kidneys, and laminae (87, 216-220). However, in studies using experimental models of sepsis-related laminitis, the increased inflammatory cytokines and leukocytes detected in the liver, lung, and kidney did not affect function of these organs $(221,235)$. Because of the significance of equine laminitis, a great deal of interest and research has focused on determining the pathophysiology of sepsis-associated lamellar injury. Laminitis experts have compared sepsis-mediated laminar injury in horses to sepsisinduced organ failure in people (222). This comparison is based on the observation that laminar changes during the prodromal and acute stages of induced laminitis in horses are similar to the changes observed in organs at risk of failure during human sepsis. These changes include increases in tissue pro-inflammatory cytokines, leukocyte activation, endothelial activation, and neutrophil tissue infiltration and accumulation $(223,224)$. Neutrophils are not only observed as being physically present in the laminae, they also contribute to the release of myeloperoxidase BWE model and epithelial injury (BWEand carbohydrate overload-model) $(218,225,236)$. Whether or not neutrophils are a target for decreasing the risk of sepsisassociated laminitis in the horse is a question that remains to be answered. Digital cryotherapy, achieved by applying ice to the distal limbs by bucket or boot, inhibits the accumulation of neutrophils in the laminae as well as the upregulation of proinflammatory cytokines (226-228). Icing the equine digit also decreases lamellar gene expression of the neutrophil chemokines CXCL1, -6 and -8 (229) and decreases expression of the leukocyte adhesion molecules ICAM and E-selectin (228). In numerous animal studies, neutrophil depletion, or targeted inhibition of neutrophil-endothelial adhesion has prevented the development of sepsis-associated organ damage (230). This approach seems to be a reasonable next step in beginning to unravel the role of neutrophils in the pathophysiology of equine laminitis.

\section{EARLY GOAL DIRECTED THERAPY IN SEPSIS}

Of all of the potential therapies investigated for the treatment of human sepsis over the past 20 years, the most significant positive impact on human mortality came from research in the early 1990s which established early goal-directed therapy (EGDT) (2). EGDT is a systematic approach to resuscitation of the severely septic and septic shock patient, and it is comprised of early identification of high-risk patients, culture collection, appropriate antimicrobial therapy, and infection source control, followed by aggressive management of hemodynamic parameters. Its principles aim to optimize oxygen delivery to tissues through the rapid stabilization of cardiac preload, afterload and contractility (231). Therapies utilized to achieve this goal include fluids, vasopressors, or vasodilators (as indicated) and the option of intubation and mechanical ventilation. Routinely measured patient parameters used to guide therapy include central venous pressure (CVP), mean arterial pressure (MAP), mixed venous oxygen saturation (SvO2), and urine output.

After a 3-year randomized controlled clinical trial (19972000) and more than a decade of national and international reliability and feasibility testing, EGDT became an established component of the "sepsis resuscitation bundle " for the Surviving Sepsis Campaign (SSC) (232). In an attempt to improve upon EGDT, in 2014 and 2015 three different groups published trials with versions of EGDT called ProCESS (Protocol-Based Care for Early Septic Shock), ARISE (Australian Resuscitation in Sepsis Evaluation) and ProMISe (Protocolized Management in Sepsis) (231). These trials were referred to as the "trio of EGDT trials." Compared to the $30.5 \%$ mortality rate of the 1997-2000 EGDT trial, the reported sepsis mortality rates of 18.2, 14.5, and $25.6 \%$ for the ProCESS, ARISE, and ProMISe trials, respectively, appeared to be a significant improvement. However, due to differences in study design between the "trio trials" and the EGDT trial, such as time to patient enrollment, high rates of eligible patient exclusion, significant differences in hemodynamic phenotype of patients at baseline and an overall declining sepsis mortality rate in the United States, it is very difficult to compare the results of the "trio trials" to the original EGDT trial. Differences between the 1997-2000 EGDT trial and the "trio of EGDT trials" included: screening using SIRS, fluid challenge and lactate for inclusion in the "trio trials" compared to no screening criteria in the EGDT trial, lower initial fluid volume of 1 liter bolus in the "trio trials" compared to the 20$30 \mathrm{~mL} / \mathrm{kg}$ in the EGDT trial, majority of care provided in ICU for "trio trials" compared to emergency department care for the EGDT trial, lower rate of mechanical ventilation for the "trio trials," $50 \%$ more vasopressor use in the "trio trials" compared to the EGDT trial, steroid use of $8-37 \%$ in the "trio trials" compared to no steroids in the EGDT trial and a mortality benefit if antibiotics were administrated within the first $6 \mathrm{~h}$ in the "trio trials" (231).

The use of EGDT in equine medicine and critical care is gaining attention (233). While $\mathrm{SvO} 2$ is not routinely measured in equine patients at this time, other measures of tissue oxygenation 
include $\mathrm{pH}$, base excess (BE) and lactate. In human medicine, "resuscitation endpoints" for EGDT are clearly defined. Although similar endpoints are not defined for the horse, it is likely that agreement on such parameters will aid equine critical care specialists with the application of these therapeutic principles.

\section{NEUTROPHILS AS THERAPEUTIC TARGETS FOR SEPSIS}

In the February 2014 issue of Nature Nanotechnology, Wang et al. demonstrate the prevention of vascular inflammation and ALI (in animal models of inflammation and sepsis, respectively) by nanoparticle targeting of neutrophils (234). The albuminderived nanoparticles, loaded with the spleen tyrosine kinase (Syk) inhibitor piceatannol, were internalized preferentially by endothelial-adherent neutrophils via cell surface Fc receptors. Because Syk is required for $\beta 2$-integrin “outside-in” signaling, these adherent neutrophils subsequently detached from the endothelium. Nanoparticles were not taken up by circulating neutrophils. This method of nanoparticle drug delivery is an important step in demonstrating the feasibility of inhibiting activated, pro-inflammatory neutrophils without inhibiting all neutrophils. This therapeutic strategy, and others like it, could lead to exciting impacts for the treatment of neutrophil-mediated organ injury and disease such as ALI, laminitis and sepsis.

\section{REFERENCES}

1. Singer M, Deutschman CS, Seymour CW, Shankar-Hari M, Annane D, Michael Bauer MD, et al. The third international consensus definitions for sepsis and septic shock (Sepsis-3). JAMA. (2016) 315:801-10. doi: 10.1001/jama.2016.0287

2. Dellinger RP, Carlet JM, Masur H, Gerlach H, Calandra T, Cohen $\mathrm{J}$, et al. Surviving sepsis campaign guidelines for management of severe sepsis and septic shock. Crit Care Med. (2004) 32:858-73. doi: 10.1097/01.CCM.0000117317.18092.E4

3. Dellinger RP, Vincent JL. The surviving sepsis campaign sepsis change bundles and clinical practice. Crit Care. (2005) 9:653-4. doi: 10.1186/cc3952

4. Hall MJ, Levant S, DeFrances CJ. Trends in Inpatient Hospital Deaths: National Hospital Discharge Survey, 2000-2010. NCHS data brief. (2013). p. $1-8$.

5. Murphy SL, Xu J, Kochanek KD. Deaths: final data for 2010. Natl Vital Stat Rep. (2013) 61:1-117.

6. Torio CM, Andrews RM. National Inpatient Hospital Costs: The Most Expensive Conditions by Payer, 2011. HCUP Statistical Brief \#160. Rockville, MD: Agency for Healthcare Researchand Quality (2013). Available online at: http://www.hcup-us.ahrq.gov/reports/statbriefs/sb160.pdf

7. Deitch EA. Animal models of sepsis and shock: a review and lessons learned. Shock. (1998) 9:1-11. doi: 10.1097/00024382-199801000-00001

8. Marshall JC, Deitch E, Moldawer LL, Opal S, Redl HT, van der Poll. Preclinical models of shock and sepsis: what can they tell us? Shock. (2005) 24(Suppl 1):1-6. doi: 10.1097/01.shk.0000191383.34066.4b

9. Buras JA, Holzmann B, Sitkovsky M. Animal models of sepsis: setting the stage. Nat Rev Drug Discov. (2005) 4:854-65. doi: 10.1038/nrd1854

10. Rittirsch D, Hoesel LM, Ward PA. The disconnect between animal models of sepsis and human sepsis. J Leukoc Biol. (2007) 81:137-43. doi: 10.1189/jlb.0806542

11. Paradis MR. Update on neonatal septicemia. Vet Clin North Am Equine Pract. (1994) 10:109-35. doi: 10.1016/S0749-0739(17)30371-1

\section{CONCLUSION}

The pathophysiology of sepsis and its associated syndromes is extremely complex, and important components not covered in this review include the roles of endothelial damage, the acute phase response, coagulation, and regulatory $\mathrm{T}$ cell responses. Given the complexity of this disease and its significant impact on equine health, more research is needed to better understand basics in pathophysiology, to justify or reject current treatment protocols and to discover new therapeutic modalities. In order to accomplish these goals, equine health professionals need to establish reliable, consistent definitions of sepsis (and its associated syndromes), as well as means for gathering and sharing real incidence and survival data.

\section{AUTHOR CONTRIBUTIONS}

The author confirms being the sole contributor of this work and has approved it for publication.

\section{FUNDING}

MS is funded by a Special Emphasis Research Career Award \#K01OD015136 from NIH Office of the Director.
12. Cohen ND. Causes of and farm management factors associated with disease and death in foals. J Am Vet Med Assoc. (1994) 204:1644-51.

13. Giguère S, Weber EJ, Sanchez LC. Factors associated with outcome and gradual improvement in survival over time in 1065 equine neonates admitted to an intensive care unit. Equine Vet J. (2017) 49:45-50. doi: $10.1111 /$ evj.12536

14. Wong DM, Ruby RE, Dembek KA, Barr BS, Reuss SM, Magdesian KG, et al. Evaluation of updated sepsis scoring systems and systemic inflammatory response syndrome criteria and their association with sepsis in equine neonates. J Vet Intern Med. (2018) 32:1185-93. doi: 10.1111/jvim.15087

15. Weber EJ, Sanchez LC, Giguère S. Re-evaluation of the sepsis score in equine neonates. Equine Vet J. (2015) 47:275-8. doi: 10.1111/evj.12279

16. Marsh PS, Palmer JE. Bacterial isolates from blood and their susceptibility patterns in critically ill foals: 543 cases (1991-1998). J Am Vet Med Assoc. (2001) 218:1608-10. doi: 10.2460/javma.2001.218.1608

17. Gayle JM, Cohen ND, Chaffin MK. Factors associated with survival in septicemic foals: 65 cases (1988-1995). J Vet Inter Med. (1998) 12:140-6. doi: 10.1111/j.1939-1676.1998.tb02109.x

18. Corley KT, Donaldson LL, Furr MO. Arterial lactate concentration, hospital survival, sepsis and SIRS in critically ill neonatal foals. Equine Vet J. (2005) 37:53-9. doi: 10.2746/0425164054406856

19. Hollis AR, Furr MO, Magdesian KG, Axon JE, Ludlow V, Boston RC, et al. Blood glucose concentrations in critically ill neonatal foals. J Vet Intern Med. (2008) 22:1223-7. doi: 10.1111/j.1939-1676.2008.0174.x

20. Raisis AL, Hodgson JL, Hodgson DR. Equine neonatal septicaemia: 24 cases. Aust Vet J. (1996) 73:137-40. doi: 10.1111/j.1751-0813.1996.tb10006.x

21. Barton MH, Morris DD, Norton N, Prasse KW. Hemostatic and fibrinolytic indices in neonatal foals with presumed septicemia. J Vet Intern Med. (1998) 12:26-35. doi: 10.1111/j.1939-1676.1998.tb00493.x

22. Sanchez LC, Giguère S, Lester G D. Factors associated with survival of neonatal foals with bacteremia and racing performance of surviving thoroughbreds: 423 cases (1982-2007). J Am Vet Med Assoc. (2008) 233:1446-52. doi: 10.2460/javma.233.9.1446 
23. Peek SF, Darien BJ, Semrad SD, McGuirk S, Lien L, Riseberg A. A Prospective Study of Neonatal Septicemia and Factors Influencing Survival 60-62. Lexington, KY: American Association of Equine Practitioners (AAEP). (2004)

24. Arroyo MG, Slovis NM, Moore GE, Taylor SD. Factors associated with survival in 97 horses with septic pleuropneumonia. J Vet Intern Med. (2017) 31:894-900. doi: 10.1111/jvim.14679

25. Fogle J, Jacob M, Blikslager A, Edwards A, Wagner B, Dean K, et al. Comparison of lipopolysaccharides and soluble CD14 measurement between clinically endotoxaemic and nonendotoxaemic horses. Equine Vet J. (2017) 49:155-9. doi: 10.1111/evj.12582

26. Senior JM, Proudman CJ, Leuwer M, Carter SD. Plasma endotoxin in horses presented to an equine referral hospital: correlation to selected clinical parameters and outcomes. Equine Vet J. (2011) 43:585-91. doi: 10.1111/j.2042-3306.2010.00328.x

27. Roy MF, Kwong GP, Lambert J, Massie S, Lockhart S. Prognostic value and development of a scoring system in horses with systemic inflammatory response syndrome. J Vet Intern Med. (2017) 31:582-92. doi: $10.1111 /$ jvim. 14670

28. Lambert JL, Fernandez NJ, Roy MF. Association of presence of band cells and toxic neutrophils with systemic inflammatory response syndrome and outcome in horses with acute disease. J Vet Intern Med. (2016) 30:1284-92. doi: $10.1111 /$ jvim. 13968

29. McConachie E, Giguère S, Barton M H. Scoring system for multiple organ dysfunction in adult horses with acute surgical gastrointestinal disease. $J$ Vet Intern Med. (2016) 30:1276-83. doi: 10.1111/jvim.14321

30. Sheats MK, Cook VL, Jones SL, Blikslager AT, Pease AP. Use of ultrasound to evaluate outcome following colic surgery for equine large colon volvulus. Equine Vet J. (2010) 42:47-52. doi: 10.2746/042516409X456040

31. Wilkins PA. What's in a word? The need for SIRS and sepsis definitions in equine medicine and surgery. Equine Vet J. (2018) 50:7-9. doi: 10.1111/evj.12780

32. Bone RC, Balk RA, Cerra FB, Dellinger RP, Fein AM, Knaus WA, et al. Definitions for sepsis and organ failure and guidelines for the use of innovative therapies in sepsis. The ACCP/SCCM consensus conference committee. american college of chest physicians/society of critical care medicine. Chest. (1992) 101:1644-55. doi: 10.1378/chest.101.6.1644

33. Bertram A, Zhang H, von Vietinghoff S, de Pablo C, Haller H, Shushakova N, et al. Protein kinase C-theta is required for murine neutrophil recruitment and adhesion strengthening under flow. J Immunol. (2012) 188:4043-51. doi: 10.4049/jimmunol.1101651

34. Levy MM, Fink MP, Marshall JC, Abraham E, Angus D, Cook D, et al. 2001 SCCM/ESICM/ACCP/ATS/SIS international sepsis definitions conference. Intensive Care Med. (2003) 29:530-8. doi: 10.1007/s00134-003-1662-X

35. Moore JN, Vandenplas M L. Is it the systemic inflammatory response syndrome or endotoxemia in horses with colic? Vet Clin North Am Equine Pract. (2014) 30:337-51. doi: 10.1016/j.cveq.2014.04.003

36. Palmer J. Update on the management of neonatal sepsis in horses. Vet Clin North Am Equine Pract. (2014) 30:317-36. doi: 10.1016/j.cveq.2014. 04.005

37. Epstein KL, Brainard BM, Gomez-Ibanez SE, Lopes MA, Barton MH, Moore JN. Thrombelastography in horses with acute gastrointestinal disease. J Vet Inter Med. (2011) 25:307-14. doi: 10.1111/j.1939-1676.2010.0673.x

38. Bone RC. Immunologic dissonance: a continuing evolution in our understanding of the systemic inflammatory response syndrome (SIRS) and the multiple organ dysfunction syndrome (MODS). Ann Int Med. (1996) 125:680-7. doi: 10.7326/0003-4819-125-8-199610150-00009

39. Bone RC. Sir isaac newton, sepsis, SIRS, and CARS. Crit Care Med. (1996) 24:1125-8. doi: 10.1097/00003246-199607000-00010

40. Bone RC. Toward a theory regarding the pathogenesis of the systemic inflammatory response syndrome: what we do and do not know about cytokine regulation. Crit Care Med. (1996) 24:163-72. doi: 10.1097/00003246-199601000-00026

41. Vincent JL. Dear SIRS, I'm sorry to say that I don't like you. Crit Care Med. (1997) 25:372-4. doi: 10.1097/00003246-199702000-00029

42. Abraham E. Why immunomodulatory therapies have not worked in sepsis. Intensive Care Med. (1999) 25:556-66. doi: 10.1007/s001340050903
43. Pittet D, Rangel-Frausto S, Li N, Tarara D, Costigan M, Rempe L, et al. Systemic inflammatory response syndrome, sepsis, severe sepsis and septic shock: incidence, morbidities and outcomes in surgical ICU patients. Intensive Care Med. (1995) 21:302-9. doi: 10.1007/BF01705408

44. Rangel-Frausto MS, Pittet D, Costigan M, Hwang T, Davis CS, Wenzel RP. The natural history of the systemic inflammatory response syndrome (SIRS). A prospective study. JAMA. (1995) 273:117-23. doi: 10.1001/jama.1995.03520260039030

45. Salvo I, de Cian W, Musicco M, Langer M, Piadena R, Wolfler A, et al. The Italian SEPSIS study: preliminary results on the incidence and evolution of SIRS, sepsis, severe sepsis and septic shock. Intensive Care Med. (1995) 21(Suppl 2):S244-9. doi: 10.1007/BF01740762

46. Bossink AW, Groeneveld J, Hack CE, Thijs LG. Prediction of mortality in febrile medical patients: how useful are systemic inflammatory response syndrome and sepsis criteria? Chest. (1998) 113:1533-41. doi: 10.1378/chest.113.6.1533

47. Brun-Buisson C, Doyon F, Carlet J, Dellamonica P, Gouin F, Lepoutre $A$, et al. Incidence, risk factors, and outcome of severe sepsis and septic shock in adults. A multicenter prospective study in intensive care units French ICU group for severe sepsis. JAMA. (1995) 274:968-74. doi: 10.1001/jama.1995.03530120060042

48. Borchers A, Wilkins PA, Marsh PM, Axon JE, Read J, Castagnetti $\mathrm{C}$, et al. Sequential L-lactate concentration in hospitalised equine neonates: a prospective multicentre study. Equine Vet J. (2013) 2013:2-7. doi: 10.1111/evj.12165

49. Nemzek, J. Ean A, Marta Agrodnia D, Joe Hauptman G. Breedspecific pro-inflammatory cytokine production as a predisposing factor for susceptibility to sepsis in the dog. $J$ Vet Emerg Crit Care. (2007) 17:368-72. doi: 10.1111/j.1476-4431.2006.00215.x

50. Figueiredo MD, Vandenplas ML, Hurley DJ, Moore JN. Differential induction of MyD88- and TRIF-dependent pathways in equine monocytes by Toll-like receptor agonists. Vet Immunol Immunopathol. (2009) 127:12534. doi: 10.1016/j.vetimm.2008.09.028

51. Pacholewska A, Marti E, Leeb T, Jagannathan V, Gerber V. LPS-induced modules of co-expressed genes in equine peripheral blood mononuclear cells. BMC Genom. (2017) 18:34. doi: 10.1186/s12864-016-3390-y

52. Hart KA, Wochele DM, Norton NA, McFarlane D, Wooldridge AA, Frank $\mathrm{N}$. Effect of age, season, body condition, and endocrine status on serum free cortisol fraction and insulin concentration in horses. J Vet Intern Med. (2016) 30:653-63. doi: 10.1111/jvim.13839

53. Hinchcliff KW, Rush BR, Farris JW. Evaluation of plasma catecholamine and serum cortisol concentrations in horses with colic. J Am Vet Med Assoc. (2005) 227:276-80. doi: 10.2460/javma.2005.227.276

54. Hoffman CJ, McKenzie HC, Furr MO, Desrochers A. Glucocorticoid receptor density and binding affinity in healthy horses and horses with systemic inflammatory response syndrome. J Vet Intern Med. (2015) 29:62635. doi: 10.1111/jvim. 12558

55. Alder MN, Opoka AM, Wong HR. The glucocorticoid receptor and cortisol levels in pediatric septic shock. Crit Care. (2018) 22:244. doi: 10.1186/s13054-018-2177-8

56. Martin GS, Mannino DM, Eaton S, Moss M. The epidemiology of sepsis in the United States from 1979 through 2000. N Engl J Med. (2003) 348:154654. doi: 10.1056/NEJMoa022139

57. Martin GS. Sepsis, severe sepsis and septic shock: changes in incidence, pathogens and outcomes. Exp Rev Anti-Infect Ther. (2012) 10:701-6. doi: 10.1586/eri.12.50

58. Corley KT, Pearce G, Magdesian KG, Wilson WD. Bacteraemia in neonatal foals: clinicopathological differences between Gram-positive and Gramnegative infections, and single organism and mixed infections. Equine Vet J. (2007) 39:84-9. doi: 10.2746/042516407X157585

59. Declue AE, Johnson PJ, Day JL, Amorim JR, Honaker AR. Pathogen associated molecular pattern motifs from Gram-positive and Gram-negative bacteria induce different inflammatory mediator profiles in equine blood. Vet J. (2012) 192:455-60. doi: 10.1016/j.tvj1.2011.09.001

60. Hytychová T, Bezděková B. Retrospective evaluation of blood culture isolates and sepsis survival rate in foals in the Czech Republic: 50 cases (2011-2013). J Vet Emerg Crit Care. (2015) 25:660-6. doi: 10.1111/vec.12348 
61. Wereszka MM, White NA, Furr MO. Factors associated with outcome following treatment of horses with septic tenosynovitis: 51 cases (1986-2003). J Am Vet Med Assoc. (2007) 230:1195-200. doi: 10.2460/javma.230.8.1195

62. Russell CM, Axon JE, Blishen A, Begg AP. Blood culture isolates and antimicrobial sensitivities from 427 critically ill neonatal foals. Aust Vet J. (2008) 86:266-71. doi: 10.1111/j.1751-0813.2008.00311.x

63. Johns I, Tennent-Brown B, Schaer BD, Southwood L, Boston R, Wilkins P. Blood culture status in mature horses with diarrhoea: a possible association with survival. Equine Vet J. (2009) 41:160-4. doi: 10.2746/042516409X360208

64. Peek SF, Semrad S, McGuirk SM, Riseberg A, Slack JA, Marques F, et al. Prognostic value of clinicopathologic variables obtained at admission and effect of antiendotoxin plasma on survival in septic and critically ill foals. $J$ Vet Intern Med. (2006) 20:569-74. doi: 10.1111/j.1939-1676.2006.tb02898.x

65. Sutherland A, Thomas M, Brandon RA, Brandon RB, Lipman J, Tang $\mathrm{B}$, et al. Development and validation of a novel molecular biomarker diagnostic test for the early detection of sepsis. Crit Care. (2011) 15:R149. doi: $10.1186 / \mathrm{cc} 10274$

66. Faix JD. Biomarkers of sepsis. Crit Rev Clin Lab Sci. (2013) 50:23-36. doi: $10.3109 / 10408363.2013 .764490$

67. Ratzinger F, Schuardt M, Eichbichler K, Tsirkinidou I, Bauer M, Haslacher $\mathrm{H}$, et al. Utility of sepsis biomarkers and the infection probability score to discriminate sepsis and systemic inflammatory response syndrome in standard care patients. PLoS ONE. (2013) 8:e82946. doi: 10.1371/journal.pone.0082946

68. Sankar V, Webster N R. Clinical application of sepsis biomarkers. J Anesth. (2013) 27:269-83. doi: 10.1007/s00540-012-1502-7

69. Vassiliou AG, Mastora Z, Orfanos SE, Jahaj E, Maniatis NA, Koutsoukou A, et al. Elevated biomarkers of endothelial dysfunction/activation at ICU admission are associated with sepsis development. Cytokine. (2014) 69:2407. doi: 10.1016/j.cyto.2014.06.010

70. Zhang Y, Khalid S, Jiang L. Diagnostic and predictive performance of biomarkers in patients with sepsis in an intensive care unit. $J$ Int Med Res. (2019) 47:44-58. doi: 10.1177/0300060518793791

71. Magrini L, Gagliano G, Travaglino F, Vetrone F, Marino R, Cardelli P, et al. Comparison between white blood cell count, procalcitonin and $\mathrm{C}$ reactive protein as diagnostic and prognostic biomarkers of infection or sepsis in patients presenting to emergency department. Clin Chem Lab Med. (2014) 52:1465-72. doi: 10.1515/cclm-2014-0210

72. Cabral L, Afreixo V, Meireles R, Vaz M, Frade JG, Chaves C, et al. Evaluation of procalcitonin accuracy for the distinction between Gram-negative and Gram-positive bacterial sepsis in burn patients. J Burn Care Res. (2018) 40:112-9. doi: 10.1093/JBCR/IRY058

73. Yan ST, Sun LC, Jia HB, Gao W, Yang JP, Zhang GQ. Procalcitonin levels in bloodstream infections caused by different sources and species of bacteria. Am J Emerg Med. (2017) 35:579-83. doi: 10.1016/j.ajem.2016.12.017

74. Fang Y, Li C, Shao R, Yu H, Zhang Q. The role of biomarkers of endothelial activation in predicting morbidity and mortality in patients with severe sepsis and septic shock in intensive care: a prospective observational study. Thromb Res. (2018) 171:149-54. doi: 10.1016/j.thromres.2018.09.059

75. Szederjesi J, Almasy E, Lazar A, Hu?anu A, Badea I, Georgescu A. An evaluation of serum procalcitonin and c-reactive protein levels as diagnostic and prognostic biomarkers of severe sepsis. J Crit Care Med. (2015) 1:147-53. doi: 10.1515/jccm-2015-0022

76. Rieger M, Kochleus C, Teschner D, Rascher D, Barton AK, Geerlof A, et al. A new ELISA for the quantification of equine procalcitonin in plasma as potential inflammation biomarker in horses. Anal Bioanal Chem. (2014) 406:5507-12. doi: 10.1007/s00216-014-7944-Z

77. Zabrecky KA, Slovis NM, Constable PD, Taylor SD. Plasma C-reactive protein and haptoglobin concentrations in critically ill neonatal foals. $J$ Vet Intern Med. (2015) 29:673-7. doi: 10.1111/jvim.12568

78. Paltrinieri S, Giordano A, Villani M, Manfrin M, Panzani S, Veronesi MC. Influence of age and foaling on plasma protein electrophoresis and serum amyloid A and their possible role as markers of equine neonatal septicaemia. Vet J. (2008) 176:393-6. doi: 10.1016/j.tvjl.2007.05.018

79. Castagnetti C, Mariella J, Pirrone A, Cinotti S, Mari G, Peli A. Expression of interleukin-1beta, interleukin-8, and interferon-gamma in blood samples obtained from healthy and sick neonatal foals. Am J Vet Res. (2012) 73:141827. doi: 10.2460/ajvr.73.9.1418
80. Burton AB, Wagner B, Erb HN, Ainsworth DM. Serum interleukin-6 (IL-6) and IL-10 concentrations in normal and septic neonatal foals. Vet Immunol Immunopathol. (2009) 132:122-8. doi: 10.1016/j.vetimm.2009.05.006

81. Wagner B, Ainsworth DM, Freer H. Analysis of soluble CD14 and its use as a biomarker in neonatal foals with septicemia and horses with recurrent airway obstruction. Vet Immunol Immunopathol. (2013) 155:1248. doi: 10.1016/j.vetimm.2013.05.018

82. Silva A, Wagner B, McKenzie HC, Desrochers AM, Furr MO. An investigation of the role of soluble CD14 in hospitalized, sick horses. Vet Immunol Immunopathol. (2013) 155:264-9. doi: 10.1016/j.vetimm.2013.08.007

83. Steelman SM, Johnson P, Jackson A, Schulze J, Chowdhary B P. Serum metabolomics identifies citrulline as a predictor of adverse outcomes in an equine model of gut-derived sepsis. Physiol Genom. (2014) 46:339-47. doi: 10.1152/physiolgenomics.00180.2013

84. Zicker SC, Spensley MS, Rogers QR, Willits NH. Concentrations of amino acids in the plasma of neonatal foals with septicemia. Am J Vet Res. (1991) 52:1010-3.

85. Vincent JL, Moreno R, Takala J, Willatts S, De Mendonca A, Bruining H, et al. The SOFA (Sepsis-related Organ Failure Assessment) score to describe organ dysfunction/failure. On behalf of the working group on sepsis-related problems of the european society of intensive care medicine. Intensive Care Med. (1996) 22:707-10. doi: 10.1007/BF01709751

86. Marshall JC. Charting the course of critical illness: prognostication and outcome description in the intensive care unit. Crit Care Med. (1999) 27:676-8. doi: 10.1097/00003246-199904000-00005

87. Roy MF. Sepsis in adults and foals. Vet Clin North Am Equine Pract. (2004) 20:41-61. doi: 10.1016/j.cveq.2003.12.005

88. Howell MD, Talmor D, Schuetz P, Hunziker S, Jones AE, Shapiro NI. Proof of principle: the predisposition, infection, response, organ failure sepsis staging system. Crit Care Med. (2011) 39:322-7. doi: 10.1097/CCM.0b013e3182037a8e

89. Granja C, Povoa P, Lobo C, Teixeira-Pinto A, Carneiro A, CostaPereira A. The predisposition, infection, response and organ failure (Piro) sepsis classification system: results of hospital mortality using a novel concept and methodological approach. PLoS ONE. (2013) 8:e53885. doi: 10.1371/journal.pone.0053885

90. Wong DM, Wilkins PA. Defining the systemic inflammatory response syndrome in equine neonates. Vet Clin North Am Equine Pract. (2015) 31:463-81. doi: 10.1016/j.cveq.2015.08.001

91. Goldstein B, Giroir B, Randolph A, International Consensus Conference on Pediatric Sepsis. International pediatric sepsis consensus conference: definitions for sepsis and organ dysfunction in pediatrics. Pediatr Crit Care Med. (2005) 6:2-8. doi: 10.1097/01.PCC.0000149131.72248.E6

92. Brewer BD, Koterba AM. Development of a scoring system for the early diagnosis of equine neonatal sepsis. Equine Vet J. (1988) 20:18-22. doi: 10.1111/j.2042-3306.1988.tb01445.x

93. Brewer BD, Koterba AM, Carter RL, Rowe ED. Comparison of empirically developed sepsis score with a computer generated and weighted scoring system for the identification of sepsis in the equine neonate. Equine Vet J. (1988) 20:23-4.

94. Rocha e Silva M. A brief survey of the history of inflammation. Agents Actions. (1978) 8:45-9. doi: 10.1007/BF01972401

95. MacKay RJ. Inflammation in horses. The veterinary clinics of north america. Equine Pract. (2000) 16:15-27. doi: 10.1016/S0749-0739(17)30116-5

96. Iskander KN, Osuchowski MF, Stearns-Kurosawa DJ, Kurosawa S, Stepien D, Valentine C, et al. Sepsis: multiple abnormalities, heterogeneous responses, and evolving understanding. Physiol Rev. (2013) 93:1247-88. doi: 10.1152/physrev.00037.2012

97. Werners AH, Bryant CE. Pattern recognition receptors in equine endotoxaemia and sepsis. Equine Vet J. (2012) 44:490-8. doi: 10.1111/j.2042-3306.2012.00574.x

98. Chen GY, Nunez G. Sterile inflammation: sensing and reacting to damage. Nat Rev Immunol. (2010) 10:826-37. doi: 10.1038/nri2873

99. Szatmary Z. Molecular biology of toll-like receptors. Gen Physiol Biophys. (2012) 31:357-66. doi: 10.4149/gpb_2012_048

100. Tan RS, Ho B, Leung BP, Ding JL. TLR Cross-talk confers specificity to innate immunity. Int Rev Immunol. (2014) 33:443-53. doi: $10.3109 / 08830185.2014 .921164$ 
101. Williams DL, Ha T, Li C, Kalbfleisch JH, Schweitzer J, Vogt W, et al. Modulation of tissue Toll-like receptor 2 and 4 during the early phases of polymicrobial sepsis correlates with mortality. Crit Care Med. (2003) 31:1808-18. doi: 10.1097/01.CCM.0000069343.27691.F3

102. Benbarek H, Deby-Dupont G, Caudron I, Grulke S, Deby C, Lamy $\mathrm{M}$, et al. Interactions between lipopolysaccharides and blood factors on the stimulation of equine polymorphonuclear neutrophils. Vet Immunol Immunopathol. (1998) 64:313-22. doi: 10.1016/S0165-2427(98)00142-1

103. Rakoff-Nahoum S, Paglino J, Eslami-Varzaneh F, Edberg S, Medzhitov R. Recognition of commensal microflora by toll-like receptors is required for intestinal homeostasis. Cell. (2004) 118:229-41. doi: 10.1016/j.cell.2004.07.002

104. Matzinger P. Friendly and dangerous signals: is the tissue in control? Nat Immunol. (2007) 8:11-3. doi: 10.1038/ni0107-11

105. Kawai T, Akira S. Toll-like receptors and their crosstalk with other innate receptors in infection and immunity. Immunity. (2011) 34:637-50. doi: 10.1016/j.immuni.2011.05.006

106. Gornik K, Moore P, Figueiredo M, Vandenplas M. Expression of toll-like receptors 2:3, 4:6, 9, and $\mathrm{MD}-2$ in the normal equine cornea, limbus, and conjunctiva. Vet Ophthal. (2011) 14:80-5. doi: $10.1111 / j .1463-5224.2010 .00844 . x$

107. Zychlinsky A, Weinrauch Y, Weiss J. Introduction: forum in immunology on neutrophils. Microbes Infect. (2003) 5:1289-91. doi: 10.1016/j.micinf.2003.09.010

108. Schumann RR. Old and new findings on lipopolysaccharide-binding protein: a soluble pattern-recognition molecule. Biochem Soc Transac. (2011) 39:98993. doi: 10.1042/BST0390989

109. Brikos C, O'Neill LA. Signalling of toll-like receptors. Handbook Exp Pharmacol. (2008) (183):21-50. doi: 10.1007/978-3-540-72167-3_2

110. Calvano SE, Xiao W, Richards DR, Felciano RM, Baker HV, Cho RJ, et al. A network-based analysis of systemic inflammation in humans. Nature. (2005) 437:1032-7. doi: 10.1038/nature03985

111. Gomez HG, Gonzalez SM, Londono JM, Hoyos NA, Nino CD, Leon AL, et al. Immunological characterization of compensatory anti-inflammatory response syndrome in patients with severe sepsis: a longitudinal study*. Crit Care Med. (2014) 42:771-80. doi: 10.1097/CCM.0000000000000100

112. Ward NS, Casserly B, Ayala A. The compensatory anti-inflammatory response syndrome (CARS) in critically ill patients. Clin Chest Med. (2008) 29:617-25. doi: 10.1016/j.ccm.2008.06.010

113. Osuchowski MF, Craciun F, Weixelbaumer KM, Duffy ER, Remick DG, Sepsis chronically in MARS: systemic cytokine responses are always mixed regardless of the outcome, magnitude, or phase of sepsis. J Immunol. (2012) 189:4648-56. doi: 10.4049/jimmunol.1201806

114. Cudmore LA, Muurlink T, Whittem T, Bailey S R. Effects of oral clenbuterol on the clinical and inflammatory response to endotoxaemia in the horse. Res Vet Sci. (2013) 94:682-6. doi: 10.1016/j.rvsc.2013.01.003

115. Holcombe SJ, Jacobs CC, Cook VL, Gandy JC, Hauptman JG, Sordillo LM. Duration of in vivo endotoxin tolerance in horses. Vet Immunol Immunopathol. (2016) 173:10-6. doi: 10.1016/j.vetimm.2016.03.016

116. Morris DD, Crowe N, Moore J N. Correlation of clinical and laboratory data with serum tumor necrosis factor activity in horses with experimentally induced endotoxemia. Am J Vet Res. (1990) 51:1935-40.

117. Morris DD, Moore JN, Crowe N. Serum tumor necrosis factor activity in horses with colic attributable to gastrointestinal tract disease. Am J Vet Res. (1991) 52:1565-9.

118. Morris DD, Moore J N. Tumor necrosis factor activity in serum from neonatal foals with presumed septicemia. J Am Vet Med Assoc. (1991) 199:1584-9.

119. Tracey KJ, Beutler B, Lowry SF, Merryweather J, Wolpe S, Milsark IW, et al. Shock and tissue injury induced by recombinant human cachectin. Science. (1986) 234:470-4. doi: 10.1126/science.3764421

120. Okusawa S, Gelfand JA, Ikejima T, Connolly RJ, Dinarello CA. Interleukin 1 induces a shock-like state in rabbits. Synergism with tumor necrosis factor and the effect of cyclooxygenase inhibition. J Clin Invest. (1988) 81:1162-72. doi: $10.1172 / \mathrm{JCI} 113431$

121. Tadros EM, Frank N. Effects of continuous or intermittent lipopolysaccharide administration for 48 hours on the systemic inflammatory response in horses. Am J Vet Res. (2012) 73:1394-402. doi: 10.2460/ajvr.73.9.1394

122. Pusterla N, Magdesian KG, Mapes S, Leutenegger CM. Expression of molecular markers in blood of neonatal foals with sepsis. Am J Vet Res. (2006) 67:1045-9. doi: 10.2460/ajvr.67.6.1045

123. Grailer JJ, Kalbitz M, Zetoune FS, Ward PA. Persistent neutrophil dysfunction and suppression of acute lung injury in mice following cecal ligation and puncture sepsis. J Innate Immun. (2014) 6:695-705. doi: $10.1159 / 000362554$

124. Sherry RM, Cue JI, Goddard JK, Parramore JB, DiPiro JT. Interleukin-10 is associated with the development of sepsis in trauma patients. J Trauma. (1996) 40:613-6. discussion: 616-7. doi: 10.1097/00005373-199604000-00016

125. Giannoudis PV, Smith RM, Perry SL, Windsor AJ, Dickson RA, Bellamy MC. Immediate IL-10 expression following major orthopaedic trauma: relationship to anti-inflammatory response and subsequent development of sepsis. Intensive Care Med. (2000) 26:1076-81. doi: 10.1007/s001340051320

126. Monneret G, Finck ME, Venet F, Debard AL, Bohe J, et al. The antiinflammatory response dominates after septic shock: association of low monocyte HLA-DR expression and high interleukin-10 concentration. Immunol Lett. (2004) 95:193-8. doi: 10.1016/j.imlet.2004.07.009

127. Tauber AI, Chernyak L. The birth of immunology. II, Metchnikoff and his critics. Cell Immunol. (1989) 121:447-73. doi: 10.1016/0008-8749(89)90043-9

128. Sônego F, Castanheira FV, Ferreira RG, Kanashiro A, Leite CA, Nascimento DC, et al. Paradoxical roles of the neutrophil in sepsis: protective and deleterious. Front Immunol. (2016) 7:155. doi: 10.3389/fimmu.2016.00155

129. Etzioni A. Defects in the leukocyte adhesion cascade. Clin Rev Allergy Immunol. (2010) 38:54-60. doi: 10.1007/s12016-009-8132-3

130. Malech HL, Gallin JI. Current concepts: immunology. Neutrophils in human diseases. N Engl J Med. (1987) 317:687-94. doi: 10.1056/NEJM198709103171107

131. Galli SJ, Borregaard N, Wynn TA. Phenotypic and functional plasticity of cells of innate immunity: macrophages, mast cells and neutrophils. Nat Immunol. (2011) 12:1035-44. doi: 10.1038/ni.2109

132. Carakostas MC, Moore WE, Smith JE. Intravascular neutrophilic granulocyte kinetics in horses. Am J Vet Res. (1981) 42:623-5.

133. Pillay J, den Braber I, Vrisekoop N, Kwast LM, de Boer RJ, Borghans JA, et al. In vivo labeling with $2 \mathrm{H} 2 \mathrm{O}$ reveals a human neutrophil lifespan of 5.4 days. Blood. (2010) 116:625-7. doi: 10.1182/blood-2010-01-259028

134. Summers C, Rankin SM, Condliffe AM, Singh N, Peters AM, Chilvers ER. Neutrophil kinetics in health and disease. Trends Immunol. (2010) 31:318-24. doi: 10.1016/j.it.2010.05.006

135. Kolaczkowska E, Kubes P. Neutrophil recruitment and function in health and inflammation. Nat Rev Immunol. (2013) 13:159-75. doi: 10.1038/nri3399

136. Arancibia SA, Beltran CJ, Aguirre IM, Silva P, Peralta AL, Malinarich F, et al. Toll-like receptors are key participants in innate immune responses. Biol Res. (2007) 40:97-112. doi: 10.4067/S0716-97602007000200001

137. Zeytun A, Chaudhary A, Pardington P, Cary R, Gupta G. Induction of cytokines and chemokines by Toll-like receptor signaling: strategies for control of inflammation. Crit Rev Immunol. (2010) 30:53-67. doi: 10.1615/CritRevImmunol.v30.i1.40

138. Sadik CD, Luster AD. Lipid-cytokine-chemokine cascades orchestrate leukocyte recruitment in inflammation. J Leukoc Biol. (2012) 91:207-15. doi: $10.1189 / \mathrm{jlb} .0811402$

139. Sadik CD, Kim ND, Luster AD. Neutrophils cascading their way to inflammation. Trends Immunol. (2011) 32:452-60. doi: 10.1016/j.it.2011.06.008

140. Williams MR, Azcutia V, Newton G, Alcaide P, Luscinskas FW. Emerging mechanisms of neutrophil recruitment across endothelium. Trends Immunol. (2011) 32:461-9. doi: 10.1016/j.it.2011.06.009

141. Bevilacqua MP, Pober JS, Wheeler ME, Cotran RS, Gimbrone MA, Interleukin 1 acts on cultured human vascular endothelium to increase the adhesion of polymorphonuclear leukocytes, monocytes, and related leukocyte cell lines. J Clin Invest. (1985) 76:2003-11. doi: 10.1172/JCI112200

142. Gamble JR, Harlan JM, Klebanoff SJ, Vadas MA. Stimulation of the adherence of neutrophils to umbilical vein endothelium by human recombinant 
tumor necrosis factor. Proc Natl Acad Sci USA. (1985) 82:8667-71. doi: $10.1073 /$ pnas.82.24.8667

143. Schleimer RP, Rutledge BK. Cultured human vascular endothelial cells acquire adhesiveness for neutrophils after stimulation with interleukin 1, endotoxin, and tumor-promoting phorbol diesters. J Immunol. (1986) 136:649-54.

144. Mueller H, Stadtmann A, Van Aken H, Hirsch E, Wang D, Ley $\mathrm{K}$, et al. Tyrosine kinase Btk regulates E-selectin-mediated integrin activation and neutrophil recruitment by controlling phospholipase C (PLC) gamma2 and PI3Kgamma pathways. Blood. (2010) 115:3118-27. doi: 10.1182/blood-2009-11-254185

145. Yago T, Shao B, Miner JJ, Yao L, Klopocki AG, Maeda K, et al. Eselectin engages PSGL-1 and CD44 through a common signaling pathway to induce integrin alphaLbeta2-mediated slow leukocyte rolling. Blood. (2010) 116:485-94. doi: 10.1182/blood-2009-12-259556

146. Ley K, Laudanna C, Cybulsky MI, Nourshargh S. Getting to the site of inflammation: the leukocyte adhesion cascade updated. Nat Rev Immunol. (2007) 7:678-89. doi: 10.1038/nri2156

147. Nauseef WM, Borregaard N. Neutrophils at work. Nat Immunol. (2014) 15:602-11. doi: 10.1038/ni.2921

148. Schymeinsky J, Mocsai A, Walzog B. Neutrophil activation via beta2 integrins (CD11/CD18): molecular mechanisms and clinical implications. Thromb Haemost. (2007) 98:262-73. doi: 10.1160/TH07-02-0156

149. Borregaard N. Neutrophils, from marrow to microbes. Immunity. (2010) 33:657-70. doi: 10.1016/j.immuni.2010.11.011

150. Herter J, Zarbock A. Integrin regulation during leukocyte recruitment. J Immunol. (2013) 190:4451-7. doi: 10.4049/jimmunol.1203179

151. Heit B, Tavener S, Raharjo E, Kubes P. An intracellular signaling hierarchy determines direction of migration in opposing chemotactic gradients. J Cell Biol. (2002) 159:91-102. doi: 10.1083/jcb.200202114

152. Heit B, Robbins SM, Downey CM, Guan Z, Colarusso P, Miller BJ, et al. PTEN functions to 'prioritize' chemotactic cues and prevent 'distraction' in migrating neutrophils. Nat Immunol. (2008) 9:743-52. doi: 10.1038/ni.1623

153. Lilliehöök I, Tvedten HW, Bröjer J, Edner A, Nostell K. Timerelated changes in equine neutrophils after experimental endotoxemia: myeloperoxidase staining, size, and numbers. Vet Clin Pathol. (2016) 45:6672. doi: $10.1111 / \mathrm{vcp} .12334$

154. Vinther AM, Heegaard PM, Skovgaard K, Buhl R, Andreassen SM, Andersen $\mathrm{PH}$. Characterization and differentiation of equine experimental local and early systemic inflammation by expression responses of inflammationrelated genes in peripheral blood leukocytes. BMC Vet Res. (2016) 12:83. doi: 10.1186/s12917-016-0706-8

155. Anderson SL, Singh B. Neutrophil apoptosis is delayed in an equine model of colitis: implications for the development of systemic inflammatory response syndrome. Equine Vet J. (2017) 49:383-8. doi: 10.1111/evj.12576

156. Reddy RC, Standiford TJ. Effects of sepsis on neutrophil chemotaxis. Curr Opin Hematol. (2010) 17:18-24. doi: 10.1097/MOH.0b013e32833338f3

157. Hofman P. Molecular regulation of neutrophil apoptosis and potential targets for therapeutic strategy against the inflammatory process. Curr Drug Targets Inflamm Allergy. (2004) 3:1-9. doi: 10.2174/1568010043483935

158. Colotta F, Re F, Polentarutti N, Sozzani S, Mantovani A. Modulation of granulocyte survival and programmed cell death by cytokines and bacterial products. Blood. (1992) 80:2012-20.

159. Milot E, Fotouhi-Ardakani N, Filep JG. Myeloid nuclear differentiation antigen, neutrophil apoptosis and sepsis. Front Immunol. (2012) 3:397. doi: 10.3389/fimmu.2012.00397

160. Krista KM, White NA, Barrett JG, Furr MO, Buechner-Maxwell VA. Evaluation of neutrophil apoptosis in horses with acute abdominal disease. Am J Vet Res. (2013) 74:999-1004. doi: 10.2460/ajvr. 74.7.999

161. Anderson SL, Townsend HGG, Singh B. Role of toll-like receptor 4 and caspase-3,-8, and -9 in lipopolysaccharide-induced delay of apoptosis in equine neutrophils. Am J Vet Res. (2018) 79:424-32. doi: 10.2460/ajvr.79.4.424

162. Drifte G, Dunn-Siegrist I, Tissieres P, Pugin J. Innate immune functions of immature neutrophils in patients with sepsis and severe systemic inflammatory response syndrome. Crit Care Med. (2013) 41:820-32. doi: 10.1097/CCM.0b013e318274647d
163. Kipnis E. Neutrophils in sepsis: battle of the bands. Crit Care Med. (2013) 41:925-6. doi: 10.1097/CCM.0b013e31828042d8

164. van der Geest PJ, Mohseni M, Brouwer RB, van der Hoven, Steyerberg EW, Groeneveld AB. Immature granulocytes predict microbial infection and its adverse sequelae in the intensive care unit. J Crit Care. (2014) 29:523-7. doi: $10.1016 /$ j.jcrc.2014.03.033

165. Mare TA, Treacher DF, Shankar-Hari M, Beale R, Lewis SM, Chambers DJ, et al. The diagnostic and prognostic significance of monitoring blood levels of immature neutrophils in patients with systemic inflammation. Crit Care. (2015) 19:57. doi: 10.1186/s13054-015-0778-z

166. Nigro KG, O’Riordan M, Molloy EJ, Walsh MC, Sandhaus LM. Performance of an automated immature granulocyte count as a predictor of neonatal sepsis. Am J Clin Pathol. (2005) 123:618-24. doi: 10.1309/73H7K7UBW816PBJJ

167. Nierhaus A, Klatte S, Linssen J, Eismann NM, Wichmann D, Hedke J, et al. Revisiting the white blood cell count: immature granulocytes count as a diagnostic marker to discriminate between SIRS and sepsis-a prospective, observational study. BMC Immunol. (2013) 14:8. doi: 10.1186/1471-2172-14-8

168. Troì R, Agnoli C, Calipa S, Segalina S, Murgia E, Gruarin M, et al. Evaluation of the delta neutrophil index from an automated blood cell analyser in septic dogs. Vet J. (2017) 230:13-9. doi: 10.1016/j.tvjl.2017.11.002

169. Weiss DJ, Evanson OA. Evaluation of activated neutrophils in the blood of horses with colic. Am J Vet Res. (2003) 64:1364-8. doi: 10.2460/ajvr.2003.64.1364

170. Koterba AM, Brewer BD, Tarplee FA. Clinical and clinicopathological characteristics of the septicaemic neonatal foal: review of 38 cases. Equine Vet J. (1984) 16:376-82. doi: 10.1111/j.2042-3306.1984.tb01950.x

171. Hinshaw LB. Sepsis/septic shock: participation of the microcirculation: an abbreviated review. Crit Care Med. (1996) 24:1072-8. doi: 10.1097/00003246-199606000-00031

172. Saito H, Lai J, Rogers R, Doerschuk CM. Mechanical properties of rat bone marrow and circulating neutrophils and their responses to inflammatory mediators. Blood. (2002) 99:2207-13. doi: 10.1182/blood.V99.6.2207

173. Skoutelis AT, Kaleridis V, Athanassiou GM, Kokkinis KI, Missirlis YF, Bassaris HP. Neutrophil deformability in patients with sepsis, septic shock, and adult respiratory distress syndrome. Crit Care Med. (2000) 28:2355-9. doi: 10.1097/00003246-200007000-00029

174. Yoshida K, Kondo R, Wang Q, Doerschuk CM. Neutrophil cytoskeletal rearrangements during capillary sequestration in bacterial pneumonia in rats. Am J Res Crit Care Med. (2006) 174:689-98. doi: 10.1164/rccm.200502-276OC

175. Weiss DJ, Evanson OA. Evaluation of lipopolysaccharide-induced activation of equine neutrophils. Am J Vet Res. (2002) 63:811-5. doi: 10.2460/ajvr.2002.63.811

176. Alves-Filho JC, Spiller F, Cunha FQ. Neutrophil paralysis in sepsis. Shock. (2010) 34(Suppl 1):15-21. doi: 10.1097/SHK.0b013e3181e7e61b

177. Cummings CJ, Martin TR, Frevert CW, Quan JM, Wong VA, Mongovin SM, et al. Expression and function of the chemokine receptors CXCR1 and CXCR2 in sepsis. J Immunol. (1999) 162:2341-6.

178. Souto FO, Alves-Filho JC, Turato WM, Auxiliadora-Martins M, Basile-Filho A, Cunha FQ. Essential role of CCR2 in neutrophil tissue infiltration and multiple organ dysfunction in sepsis. Am J Resp Crit Care Med. (2011) 183:234-42. doi: 10.1164/rccm.201003-0416OC

179. Zhou MT, Chen CS, Chen BC, Zhang QY, Andersson R. Acute lung injury and ARDS in acute pancreatitis: mechanisms and potential intervention. World J Gastroenterol. (2010) 16:2094-9. doi: 10.3748/wjg.v16.i17.2094

180. Brown KA, Brain SD, Pearson JD, Edgeworth JD, Lewis SM, Treacher DF. Neutrophils in development of multiple organ failure in sepsis. Lancet. (2006) 368:157-69. doi: 10.1016/S0140-6736(06)69005-3

181. Luscinskas FW, Kiely JM, Ding H, Obin MS, Hebert CA, Gimbrone $\mathrm{MA}$, et al. In vitro inhibitory effect of IL-8 and other chemoattractants on neutrophil-endothelial adhesive interactions. J Immunol. (1992) 149:2163-71.

182. Ward PA. The dark side of C5a in sepsis. Nat Rev Immunol. (2004) 4:133-42. doi: 10.1038/nri1269

183. Otsuka Y, Nagano K, Hori KJ, Oh-ishi, Hayashi H, Watanabe N, et al. Inhibition of neutrophil migration by tumor necrosis factor. Ex vivo 
and in vivo studies in comparison with in vitro effect. J Immunol. (1990) 145:2639-43.

184. Ferrante A. Activation of neutrophils by interleukins-1 and-2 and tumor necrosis factors. Immunol Ser. (1992) 57:417-36.

185. Brooks AC, Rickards KJ, Cunningham FM. CXCL8 attenuates chemoattractant-induced equine neutrophil migration. Vet Immunol Immunopathol. (2011) 139:141-7. doi: 10.1016/j.vetimm.2010.09.008

186. Kovach MA, Standiford TJ. The function of neutrophils in sepsis. Curr Opin Infect Dis. (2012) 25:321-7. doi: 10.1097/QCO.0b013e3283528c9b

187. Moraes TJ, Zurawska JH, Downey GP. Neutrophil granule contents in the pathogenesis of lung injury. Curr Opin Hematol. (2006) 13:21-7. doi: 10.1097/01.moh.0000190113.31027.d5

188. Fialkow L, Wang Y, Downey GP. Reactive oxygen and nitrogen species as signaling molecules regulating neutrophil function. Free Radic Biol Med. (2007) 42:153-64. doi: 10.1016/j.freeradbiomed.2006.09.030

189. Tang BM, McLean AS, Dawes IW, Huang SJ, Lin RC. The use of geneexpression profiling to identify candidate genes in human sepsis. Am J Res Crit Care Med. (2007) 176:676-84. doi: 10.1164/rccm.200612-1819OC

190. Delano MJ, Thayer T, Gabrilovich S, Kelly-Scumpia KM, Winfield RD, Scumpia PO, et al. Sepsis induces early alterations in innate immunity that impact mortality to secondary infection. J Immunol. (2011) 186:195-202. doi: 10.4049/jimmunol.1002104

191. Danikas DD, Karakantza M, Theodorou GL, Sakellaropoulos GC, Gogos CA. Prognostic value of phagocytic activity of neutrophils and monocytes in sepsis. Correlation to CD64 and CD14 antigen expression. Clin Exp Immunol. (2008) 154:87-97. doi: 10.1111/j.1365-2249.2008.03737.x

192. McTaggart C, Penhale J, Raidala S L. Effect of plasma transfusion on neutrophil function in healthy and septic foals. Aust Vet J. (2005) 83:499505. doi: 10.1111/j.1751-0813.2005.tb13304.x

193. Benjamim CF, Silva JS, Fortes ZB, Oliveira MA, Ferreira SH, Cunha FQ. Inhibition of leukocyte rolling by nitric oxide during sepsis leads to reduced migration of active microbicidal neutrophils. Infec Immun. (2002) 70:360210. doi: 10.1128/IAI.70.7.3602-3610.2002

194. Santos SS, Brunialti MK, Rigato O, Machado FR, Silva E, Salomao R. Generation of nitric oxide and reactive oxygen species by neutrophils and monocytes from septic patients and association with outcomes. Shock. (2012) 38:18-23. doi: 10.1097/SHK.0b013e318257114e

195. Brinkmann V, Reichard U, Goosmann C, Fauler B, Uhlemann Y, Weiss D, et al. Neutrophil extracellular traps kill bacteria. Science. (2004) 303:1532-5. doi: 10.1126/science.1092385

196. Seeley EJ, Matthay MA, Wolters PJ. Inflection points in sepsis biology: from local defense to systemic organ injury. Am J Physiol Lung Cell Molecul Physiol. (2012) 303:L355-63. doi: 10.1152/ajplung.00069.2012

197. Clark SR, Ma AC, Tavener SA, McDonald B, Goodarzi Z, Kelly MM, et al. Platelet TLR4 activates neutrophil extracellular traps to ensnare bacteria in septic blood. Nat Med. (2007) 13:463-9. doi: 10.1038/nm1565

198. Fuchs TA, Brill A, Duerschmied D, Schatzberg D, Monestier M, Myers D, et al. Extracellular DNA traps promote thrombosis. Proc Natl Acad Sci USA. (2010) 107:15880-5. doi: 10.1073/pnas.1005743107

199. Narasaraju T, Yang E, Samy RP, Ng HH, Poh WP, Liew AA, et al. Excessive neutrophils and neutrophil extracellular traps contribute to acute lung injury of influenza pneumonitis. Am J Pathol. (2011) 179:199-210. doi: 10.1016/j.ajpath.2011.03.013

200. Letendre JA, Goggs R. Determining prognosis in canine sepsis by bedside measurement of cell-free DNA and nucleosomes. J Vet Emerg Crit Care. (2018) 28:503-11. doi: 10.1111/vec.12773

201. Xu Z, Cai J, Gao J, White GC, Chen F, Ma YQ. Interaction of kindlin-3 and $\beta 2$-integrins differentially regulates neutrophil recruitment and NET release in mice. Blood. (2015) 126:373-7. doi: 10.1182/blood-2015-03-636720

202. Nguyen DN, Stensballe A, Lai JC, Jiang P, Brunse A, Li Y, et al. Elevated levels of circulating cell-free DNA and neutrophil proteins are associated with neonatal sepsis and necrotizing enterocolitis in immature mice, pigs and infants. Innate Immun. (2017) 23:524-36. doi: 10.1177/1753425917719995

203. Patel JM, Sapey E, Parekh D, Scott A, Dosanjh D, Gao F, et al. R. Sepsis induces a dysregulated neutrophil phenotype that is associated with increased mortality. Med Inflamm. (2018) 2018:4065362. doi: $10.1155 / 2018 / 4065362$
204. Côté O, Clark ME, Viel L, Labbé G, Seah SY, Khan MA, et al. Secretoglobin $1 \mathrm{~A} 1$ and $1 \mathrm{~A} 1 \mathrm{~A}$ differentially regulate neutrophil reactive oxygen species production, phagocytosis and extracellular trap formation. PLoS ONE. (2014) 9:e96217. doi: 10.1371/journal.pone.0096217

205. Herteman N, Vargas A, Lavoie JP. Characterization of circulating lowdensity neutrophils intrinsic properties in healthy and asthmatic horses. Sci Rep. (2017) 7:7743. doi: 10.1038/s41598-017-08089-5

206. Rebordão MR, Carneiro C, Alexandre-Pires G, Brito P, Pereira C, Nunes $\mathrm{T}$, et al. Neutrophil extracellular traps formation by bacteria causing endometritis in the mare. J Reprod Immunol. (2014) 106:41-9. doi: 10.1016/j.jri.2014.08.003

207. Uberti B, Morán G. Role of neutrophils in equine asthma. Anim Health Res Rev. (2018) 19:65-73. doi: 10.1017/S146625231800004X

208. Vargas A, Boivin R, Cano P, Murcia Y, Bazin I, Lavoie JP. Neutrophil extracellular traps are downregulated by glucocorticosteroids in lungs in an equine model of asthma. Respir Res. (2017) 18:207. doi: 10.1186/s12931-017-0689-4

209. Haslett C. Resolution of acute inflammation and the role of apoptosis in the tissue fate of granulocytes. Clin Sci. (1992) 83:639-48. doi: 10.1042/cs0830639

210. Brealey D, Singer M. Multi-organ dysfunction in the critically ill: effects on different organs. J R College Phys Lond. (2000) 34:428-31.

211. Hoesel LM, Neff TA, Neff SB, Younger JG, Olle EW, Gao H, et al. Harmful and protective roles of neutrophils in sepsis. Shock. (2005) 24:40-7. doi: 10.1097/01.shk.0000170353.80318.d5

212. Guo RF, Riedemann NC, Laudes IJ, Sarma VJ, Kunkel RG, Dilley KA, et al. Altered neutrophil trafficking during sepsis. J Immunol. (2002) 169:307-14. doi: 10.4049/jimmunol.169.1.307

213. Abraham E. Neutrophils and acute lung injury. Crit Care Med. (2003) 31 (Suppl 4):S195-9. doi: 10.1097/01.CCM.0000057843.47705.E8

214. Steinberg KP, Milberg JA, Martin TR, Maunder RJ, Cockrill BA, Hudson LD. Evolution of bronchoalveolar cell populations in the adult respiratory distress syndrome. Am J Res Crit Care Med. (1994) 150:113-22. doi: 10.1164/ajrccm.150.1.8025736

215. Neumann B, Zantl N, Veihelmann A, Emmanuilidis K, Pfeffer K, Heidecke C, et al. Mechanisms of acute inflammatory lung injury induced by abdominal sepsis. Int Immunol. (1999) 11:217-27. doi: 10.1093/intimm/11.2.217

216. Cotovio M, Monreal L, Armengou L, Prada J, Almeida JM, Segura D. Fibrin deposits and organ failure in newborn foals with severe septicemia. J Vet Inter Med. (2008) 22:1403-10. doi: 10.1111/j.1939-1676.2008.0178.x

217. Faleiros RR, Macoris DG, Alves GE, Souza DG, Teixeira MM, Moore RM. Local and remote lesions in horses subjected to small colon distension and decompression. Can J Vet Res. (2008) 72:68-76.

218. Faleiros RR, Johnson PJ, Nuovo GJ, Messer NT, Black SJ, Belknap JK. Laminar leukocyte accumulation in horses with carbohydrate overload-induced laminitis. J Vet Inter Med. (2011) 25:107-15. doi: 10.1111/j.1939-1676.2010.0650.x

219. Reddy AJ, Woods C, Welty-Wolf KE. Eastern equine encephalitis leading to multi-organ failure and sepsis. J Clin Virol. (2008) 42:418-21. doi: 10.1016/j.jcv.2008.03.008

220. Montgomery JB, Hamblin B, Suri SS, Johnson LE, New D, Johnston J, et al. Remote lung injury after experimental intestinal ischemia-reperfusion in horses. Histol Histopathol. (2014) 29:361-75. doi: 10.14670/HH-29.361

221. Stewart AJ, Pettigrew A, Cochran AM, Belknap JK. Indices of inflammation in the lung and liver in the early stages of the black walnut extract model of equine laminitis. Vet Immunol Immunopathol. (2009) 129:254-60. doi: 10.1016/j.vetimm.2008.11.001

222. Leise B. The role of neutrophils in equine laminitis. Cell Tissue Res. (2018) 371:541-50. doi: 10.1007/s00441-018-2788-z

223. Belknap JK, Moore JN, Crouser EC. Sepsis-From human organ failure to laminar failure. Vet Immunol Immunopathol. (2009) 129:155-7. doi: 10.1016/j.vetimm.2008.11.013

224. Belknap JK, Black SJ. Sepsis-related laminitis. Equine Vet J. (2012) 44:738-40. doi: 10.1111/j.2042-3306.2012.00668.x

225. Riggs LM, Franck T, Moore JN, Krunkosky TM, Hurley DJ, Peroni JF, et al. Neutrophil myeloperoxidase measurements in plasma, laminar tissue, and 
skin of horses given black walnut extract. Am J Vet Res. (2007) 68:81-6. doi: 10.2460/ajvr.68.1.81

226. Dern K, Watts M, Werle B, van Eps A, Pollitt C, Belknap J. Effect of delayed digital hypothermia on lamellar inflammatory signaling in the oligofructose laminitis model. J Vet Intern Med. (2017) 31:575-81. doi: 10.1111/jvim.14633

227. Dern K, van Eps A, Wittum T, Watts M, Pollitt C, Belknap J. Effect of continuous digital hypothermia on lamellar inflammatory signaling when applied at a clinically-relevant timepoint in the oligofructose laminitis model. J Vet Intern Med. (2018) 32:450-8. doi: 10.1111/jvim.15027

228. Godman JD, Burns TA, Kelly CS, Watts MR, Leise BS, Schroeder EL, et al. The effect of hypothermia on influx of leukocytes in the digital lamellae of horses with oligofructose-induced laminitis. Vet Immunol Immunopathol. (2016) 178:22-8. doi: 10.1016/j.vetimm.2016.05.013

229. van Eps AW, Leise BS, Watts M, Pollitt CC, Belknap JK. Digital hypothermia inhibits early lamellar inflammatory signalling in the oligofructose laminitis model. Equine Vet J. (2012) 44:230-7. doi: 10.1111/j.2042-3306.2011.00416.x

230. Shen XF, Cao K, Jiang JP, Guan WX, Du JF. Neutrophil dysregulation during sepsis: an overview and update. J Cell Mol Med. (2017) 21:1687-97. doi: $10.1111 / \mathrm{jcmm} .13112$

231. Nguyen HB, Jaehne AK, Jayaprakash N, Semler MW, Hegab S, Yataco AC, et al. Early goal-directed therapy in severe sepsis and septic shock: insights and comparisons to ProCESS, ProMISe, and ARISE. Crit Care. (2016) 20:160. doi: 10.1186/s13054-016-1288-3

232. Dellinger RP, Levy MM, Rhodes A, Annane D, Gerlach H, Opal SM, et al. Surviving Sepsis Campaign: international guidelines for management of severe sepsis and septic shock: (2012). Intensive Care Med. (2013) 39:165228. doi: 10.1007/s00134-012-2769-8
233. Boesch JM. Anesthesia for the horse with colic. Vet Clin North Am Equine Pract. (2013) 29:193-214. doi: 10.1016/j.cveq.2012.11.005

234. Wang Z, Li J, Cho J, Malik AB. Prevention of vascular inflammation by nanoparticle targeting of adherent neutrophils. Nat Nanotechnol. (2014) 9:204-10. doi: 10.1038/nnano.2014.17

235. Leise BS, Watts M, Johnson PJ, Black SJ, Belknap J. Inflammatory gene expression in the liver, lung and kidney in carbohydrate overload model of equine laminitis. $J$ Equine Vet Sci. (2011) 31:566-7. doi: 10.1016/j.jevs.2011.09.011

236. Leise BS, Faleiros RR, Watts $M$, Johnson PJ, Black SJ, Belknap JK. Laminar inflammatory gene expression in the carbohydrate overload model of equine laminitis. Equine Vet J. (2011) 43:54-61. doi: 10.1111/j.2042-3306.2010.00122.x

237. Mirsadraee S, Oswal D, Alizadeh Y, Caulo A, van Beek E Jr. The 7th lung cancer TNM classification and staging system: review of the changes and implications. World J Radiol. (2012) 4:128-34. doi: 10.4329/wjr.v4.i4.128

Conflict of Interest Statement: The author declares that the research was conducted in the absence of any commercial or financial relationships that could be construed as a potential conflict of interest.

Copyright (c) 2019 Sheats. This is an open-access article distributed under the terms of the Creative Commons Attribution License (CC BY). The use, distribution or reproduction in other forums is permitted, provided the original author(s) and the copyright owner(s) are credited and that the original publication in this journal is cited, in accordance with accepted academic practice. No use, distribution or reproduction is permitted which does not comply with these terms. 